\title{
Low-resolution sequencing of Rhodobacter sphaeroides 2.4.1T: chromosome II is a true chromosome
}

\author{
M. Choudhary, ${ }^{1}$ C. Mackenzie, ${ }^{1}$ K. Nereng, ${ }^{1}$ Erica Sodergren, ${ }^{2}$ \\ G. M. Weinstock ${ }^{1,2}$ and S. Kaplan ${ }^{1}$
}

Author for correspondence: S. Kaplan. Tel: +1713 500 5502. Fax: +17135005499. e-mail: skaplan@utmmg.med.uth.tmc.edu

Department of

Microbiology \& Molecular Genetics' and Department of Biochemistry \& Molecular Biology, ${ }^{2}$ The University of Texas Health Science Center, Houston, TX 77225, USA

\begin{abstract}
The photosynthetic bacterium Rhodobacter sphaeroides $2.4 .1^{\top}$ has two chromosomes, $\mathrm{Cl}(\sim 3.0 \mathrm{Mb})$ and $\mathrm{CII}(\sim 0.9 \mathrm{Mb})$. In this study a low-redundancy sequencing strategy was adopted to analyse 23 out of 47 cosmids from an ordered CII library. The sum of the lengths of these 23 cosmid inserts was $\sim 495 \mathrm{~kb}$, which comprised $\sim 417 \mathrm{~kb}$ of unique DNA. A total of 1145 sequencing runs was carried out, with each run generating $559 \pm 268$ bases of sequence to give $\sim 640 \mathrm{~kb}$ of total sequence. After editing, $\sim 2.8 \%$ bases per run were estimated to be ambiguous. After the removal of vector and Escherichia coli sequences, the remaining $\sim 565 \mathrm{~kb}$ of $R$. sphaeroides sequences were assembled, generating $\sim 291 \mathrm{~kb}$ of unique sequences. BLASTX analysis of these unique sequences suggested that $\sim 131 \mathrm{~kb}$ (45\% of the unique sequence) had matches to either known genes, or database ORFs of hypothetical or unknown function (dORFs). A total of 144 strong matches to the database was found; 101 of these matches represented genes encoding a wide variety of functions, e.g. amino acid biosynthesis, photosynthesis, nutrient transport, and various regulatory functions. Two rRNA operons ( $r m B$ and $r m C)$ and five tRNAs were also identified. The remaining $160 \mathrm{~kb}$ of DNA sequence which did not yield database matches was then analysed using CODONPREFERENCE from the GCG package. This analysis suggested that $122 \mathrm{~kb}(42 \%$ of the total unique DNA sequence) could encode putative ORFs (pORFs), with the remaining $38 \mathrm{~kb}$ (13\%) possibly representing non-coding intergenic DNA. From the data so far obtained, Cll does not appear to be specialized for encoding any particular metabolic function, physiological state or growth condition. These data suggest that Cll contains genes which are functionally as diverse as those found on any other bacterial chromosome and also contains sequences (pORFs) which may prove to be unique to this organism.
\end{abstract}

Keywords: genome analysis, sequence skimming, complex genomes, genome evolution

\section{INTRODUCTION}

Rhodobacter sphaeroides $2.4 .1^{\mathrm{T}}$ is a facultative photoheterotroph belonging to the $\alpha-3$ subdivision of the Proteobacteria (Woese et al., 1984). The metabolic diversity of this group of organisms is unparalleled (Gest, 1972; Kiley \& Kaplan, 1988). The structure and

Abbreviations: $\mathrm{Cl}$, Cll, chromosome I, II of $R$. capsulatus; dORF, database ORF (of hypothetical or unknown function); pORF, putative ORF.

The GenBank accession numbers for the sequences determined in this work are B07699-B07848. function of the photosynthetic membrane protein complexes and their regulation, photolithotrophy, nitrogen fixation, hydrogen metabolism, carbon dioxide fixation, taxis and tetrapyrrole biosynthesis, when considered in toto in $R$. sphaeroides, are remarkable. Members of the $\alpha-3$ Proteobacteria are also able to synthesize bacteriochlorophyll $a$, haem, sirohaem and vitamin $\mathrm{B}_{12}$. Numerous studies (see reviews by Woese et al., 1984; Yang et al., 1985; Gest, 1972; Kiley \& Kaplan, 1988) suggest a relationship between this group of organisms and the genesis of early mitochondrial system(s) and to the photosystem(s) of green plants. The ability of members 
of the $\alpha-3$ Proteobacteria to undergo intracellular differentiation is a unique morphogenetic connection to eukaryotes. In addition, members of this group are able to detoxify high levels of a variety of metal oxides and oxyanions (Moore \& Kaplan, 1992), which may make them useful organisms for bioremediation and some industrial processes. More recently $R$. sphaeroides $2.4 .1^{\mathrm{T}}$ has been shown to possess a genetic system for 'quorum sensing' (A. Puskas, E. P. Greenberg, S. Kaplan \& A. L. Schaefer, unpublished).

Our finding that $R$. sphaeroides $2.4 .1^{\mathrm{T}}$ contains two different circular chromosomes, $\sim 3.0$ and $\sim 0.9 \mathrm{Mbp}$ (Suwanto \& Kaplan, 1989, 1992), broke with the longheld dogma regarding our understanding of prokaryotic genome structure and organization. This discovery was rapidly followed by the finding that multiple chromosomes exist in at least four other bacterial genera, Brucella (Michaux et al., 1993), Leptospira (Zuerner et al., 1993), Agrobacterium (Allardet-Servent et al., 1993) and Pseudomonas (P. cepacia) (Cheng \& Lessie, 1994; $P$. cepacia was recently renamed Burkholderia: Rodley et al., 1995). In the case of Agrobacterium one of these chromosomes is linear. Linear chromosomes had previously been shown to exist in members of the genus Borrelia (Ferdows \& Barbour, 1989), again breaking with a long-held dogma that bacterial chromosomes are circular.

Analysis of the genomic structure of numerous independent isolates of $R$. sphaeroides reveals that most of these appear to have two chromosomes, although the chromosomes do vary in size and in the number of $r r n$ operons (K. Nereng \& S. Kaplan, unpublished) contained. A number of genes have been shown in $R$. sphaeroides $2.4 .1^{\mathrm{T}}$ to exist in duplicate copies between chromosomes I (CI) and II (CII), e.g. hemA and hem T (Neidle \& Kaplan, 1993), $r d x A$ and $r d x B$ (Neidle \& Kaplan, 1992), $c b b P_{\mathrm{I}}$ and $c b b P_{\mathrm{II}}$ (Hallenbeck et al., 1990b; Tabita et al., 1992), $c b b A_{\mathrm{I}}$ and $c b b A_{\text {II }}$ (Tabita $e t$ al., 1992; Hallenbeck et al., 1990a), rpoN ${ }_{\mathrm{I}}$ and $r p o N_{\text {II }}$ (Meijer \& Tabita, 1992; J. Zeilstra-Ryalls \& S. Kaplan, unpublished) and others. The isozymes encoded by these duplicate genes are structurally similar but in most cases are differentially regulated. Additionally, the $r r n$ operons and three tRNA genes (Dryden \& Kaplan, 1990) are dispersed between these two circular chromosomes.

Although the concept that the prokaryotic genome can consist of more than a single chromosome has gained near-universal acceptance, the kinds of genes and their distribution within the second chromosome were previously unknown. Important questions leading to an understanding of the genome complexity of $R$. sphaeroides $2.4 .1^{\mathrm{T}}$ revolve around the actual genetic content, and its organization, present on each chromosome. For example, to what extent does CII contain a duplicate set of the genes on CI? Are the gene products from CII required for specialized functions, as for plasmids? Did CII originate endogenously or was it acquired exogenously by lateral transfer?
In search of the functional role(s) underlying this genomic diversification, a detailed, albeit low-resolution, genomic analysis of CII of $R$. sphaeroides $2.4 .1^{\mathrm{T}}$ was undertaken. Towards this goal, cosmid clones hybridizing to CII were ordered from a previously constructed pLA2917 recombinant genomic library (Dryden, 1992). A high-resolution physical map of CII was derived from a set of 47 overlapping cosmid clones that covered approximately $85 \%$ of CII (Choudhary $e t$ al., 1994).

In this paper, we describe both partially and fully random sequencing strategies of 23 cosmids containing $\sim 417 \mathrm{~kb}$ of unique insert DNA previously mapped and ordered to CII. This generated $\sim 291 \mathrm{~kb}$ of unique DNA sequence. Analysis of these sequences suggested that approximately $87 \%$ of the total unique sequence was coding. That is, over $\sim 253 \mathrm{~kb}$ of DNA either gave significant database BLASTX matches $\left(P \leqslant 10^{-3}\right.$ and score $\geqslant 100$ ) to known genes or database open reading frames (dORFs) or, if not giving a database match, gave putative open reading frames (pORFs) when analysed using CODONPREFERENCE. A total of 144 database matches was found, representing a wide variety of functions. The positions of two previously described rRNA operons ( $r r n B$ and $r r n C$ ) and three tRNAs, f-Met, Ala and Ile (Dryden \& Kaplan, 1990) were confirmed. Two new tRNAs for Met and Val were also identified on this chromosome. The diverse range of metabolic functions encoded by CII suggests that CII does not appear to be specialized either for any particular metabolic role or growth condition.

\section{METHODS}

Bacterial strains, plasmids, cosmids, and growth conditions. Escherichia coli cells were grown overnight in Luria broth (LB) on a rotary shaker at $37^{\circ} \mathrm{C}$, or on LB agar plates. To maintain plasmids or cosmids in $E$. coli cultures, ampicillin $\left(100 \mu \mathrm{g} \mathrm{ml}^{-1}\right)$ or tetracycline $\left(10 \mu \mathrm{g} \mathrm{ml}^{-1}\right)$, respectively, was added to media. Recombinant plasmid subclones were screened using blue/white colour selection on LB plates containing X-Gal $\left(40 \mu \mathrm{g} \mathrm{ml}^{-1}\right)$.

Sequencing strategy. The general outline of the sequencing strategy is presented as a flowchart in Fig. 1.

Cosmid DNA preparation and the construction of libraries. Cultures of E. coli S17-1 containing previously described cosmids (Choudhary et al., 1994) were grown overnight from a single streak-purified colony. Cosmid DNA was isolated by using an alkali lysis method followed by $\mathrm{CsCl}$ gradient purification (Sambrook et al., 1989). The identity of each cosmid clone was confirmed by comparison to the previously determined SspI pattern (Choudhary et al., 1994).

Subcloning strategies. Our goal was to generate the maximum amount of sequence information for the minimum cost. We evaluated three subcloning strategies. (i) In the first case (cosmid 8536) we subcloned restriction fragments which were generated by four or five restriction enzymes which cut either rarely (fewer than three times) or not at all in the cosmid vector, but relatively frequently (5-10 times) in the cosmid insert. These restriction fragments were subcloned and then sequenced (Mackenzie et al., 1997). (ii) For cosmid 8603 we 


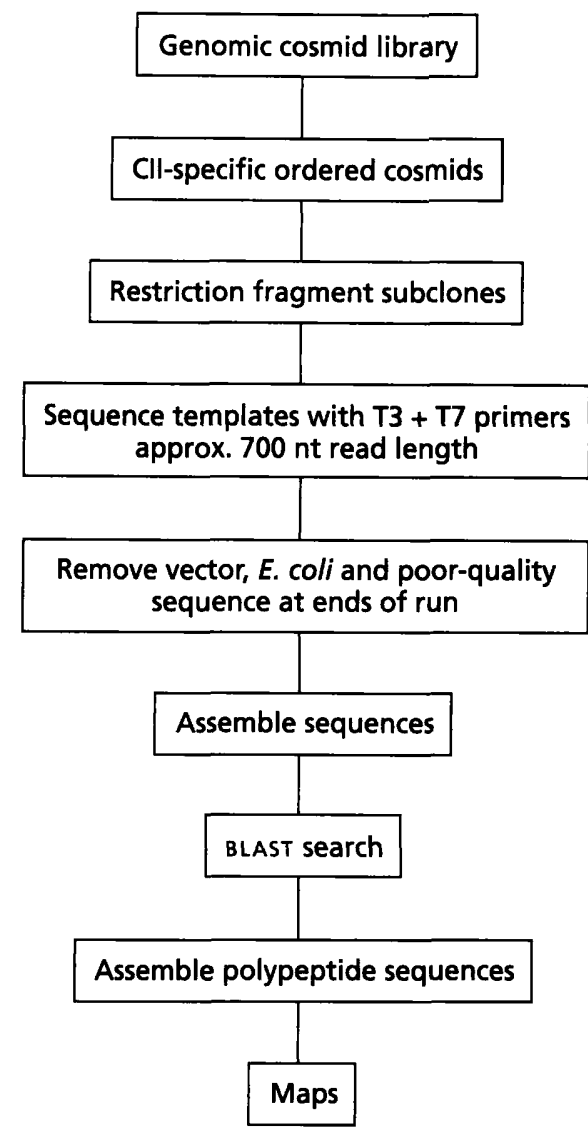

Fig. 1. Outline of the sequencing strategy.

generated a DNase I library of the total cosmid DNA, then screened the subclones by hybridization with the cosmid insert. A random sample of these insert subclones were sequenced. (iii) For cosmid 8621 we combined the strategies used for (i) and (ii) and screened a DNAse I generated library of cosmid 8621 with BamHI restriction fragments of 8621 . The BamHI restriction fragments were then subcloned and sequenced. In addition DNase I subclones which hybridized to two BamHI fragments were considered to be linking subclones and were also sequenced.

Restriction enzyme sublibraries. Cosmid DNA was fragmented by enzymic digestion, and fragments were subcloned into the compatible sites in pBluescript $\mathrm{SK}(-)$ vector. The commonly used restriction enzymes employed to construct libraries were EcoRI, BamHI, PstI, EcoRV, BglII and NotI. For each sublibrary, 96 putative clones were grown in a 96 well microtitre plate. Plasmid DNA was purified using the alkaline lysis method (Sambrook et al., 1989), and the insert clones were identified by appropriate restriction analysis. This method allowed us to rapidly screen hundreds of subclones, in order to identify those for subsequent sequencing.

DNase I sublibrary. DNase I libraries were made using the protocol of Demolis et al. (1995). Cosmid DNA was digested with RNase-free DNase I. The digest was then run on a $1 \%$ TAE low-melting-point agarose gel; fragments $\sim 1 \mathrm{~kb}$ in size were isolated and cloned into the EcoRV site of the pBluescript SK $(-)$ vector. About 1000 white transformants were picked into 96-well microtitre plates. The cultures were then pronged onto LB plates and the colonies screened by hybridization using the cosmid insert as a probe. For method (iii), the Bam HI subclones were used to rescreen the cosmid insert-specific DNase I subclones. From the hybridization data, DNase I subclones which hybridized to two $B a m H I$ fragments were considered to be linking clones. These linking clones, a number of non-linking clones and all the BamHI subclones were sequenced. From the hybridization and sequence data, a restriction map and gene order was determined.

Of the three methods described above we finally settled on method (i) as it gave an even spread of sequence information which could then be used for mapping gene order. Method (ii) proved labour intensive but did not give us the even sequence coverage we had hoped for. In addition it proved more difficult to determine gene order without the advantage of restriction site markers which were present in method (i). Method (iii) gave the best coverage and most information in terms of order. However, these advantages were offset by the considerable amount of hands-on time which was required prior to sequencing.

Template purification. We used two different plasmid purification systems, the Prep-A-Gene (Bio-Rad) or QIAwell filter (Qiagen) for template purification.

Plasmid-containing strains were grown overnight in LB medium at $37^{\circ} \mathrm{C}$. Cells were harvested in a 96 -well block by centrifugation for $5 \mathrm{~min}$ at $1500 \mathrm{~g}$. The block was covered with an adhesive tape during centrifugation to avoid crosscontamination. Cell lysates were prepared by the alkaline lysis method (see details in REAL Prep 96 plasmid kit, Qiagen) and then transferred to the QIAfilter 96-well plate using an eightchannel pipette. The lysates were precipitated following the addition of 0.7 vol. 2-propanol. The DNA pellet was washed with cold $70 \%$ ethanol and air dried. Plasmid DNA was resuspended in $200 \mu$ l distilled water.

In the Prep-A-Gene protocol, each lysate was transferred to a clean tube containing $300 \mu \mathrm{l}$ of the DNA mini-prep binding buffer provided in the kit. Then $60 \mu$ of resuspended Prep-AGene matrix was added to each tube, and the contents were mixed by pipetting up and down a few times. The mixture was applied to a spin filter which was nested inside a $1.5 \mathrm{ml}$ microfuge tube. The nested tubes were centrifuged for $30 \mathrm{~s}$; $500 \mu$ l Prep-A-Gene wash buffer was then added to each spin filter unit and recentrifuged for $30 \mathrm{~s}$. At this point each spin tube contained clean plasmid DNA. Plasmid DNA was eluted with $200 \mu$ l distilled water.

Automated sequencing. Templates were sequenced using dye-deoxy terminators purchased from $\mathrm{ABI}$ and used as recommended by the manufacturer. Primers annealing to the T3 and T7 sites of pBluescript $\mathrm{SK}(-)$ were used for sequencing restriction fragments. To sequence $D$ Nase I subclones, primers RVpBST3 (5'-GTGGATCCCCCGGGCTGCAGG-3'; $T_{m}$ $79^{\circ} \mathrm{C}$ ) and RVpBST7 (5'-CCCCCCCTCGAGGTCGACG$\left.\mathrm{GT}-3^{\prime} ; T_{\mathrm{m}} 78^{\circ} \mathrm{C}\right)$, were used. Extra insert sequence was derived from each sequencing reaction using these primers since they are closer to the EcoRV site than conventional T3 and $T 7$ primers (approximately 70 and 40 bases respectively).

The cycle sequencing programme consisted of a denaturation step at $98^{\circ} \mathrm{C}$ for $30 \mathrm{~s}$, an annealing step at $50^{\circ} \mathrm{C}$ for $15 \mathrm{~s}$, and an extension step at $60^{\circ} \mathrm{C}$ for $4 \mathrm{~min}$. Sequencing runs were performed using either an Applied Biosystems model 377 DNA sequencer as advised by the manufacturer or an ABI 373 (stretch-modified) machine. In the latter case, $5 \%(\mathrm{v} / \mathrm{v})$ Long Ranger acrylamide gels (FMC Bio Products) were used with $48 \mathrm{~cm}$ plates. These were run for $14 \mathrm{~h}$ with $36 \mathrm{~W}$ constant power. The use of longer run times combined with the other 
modifications effectively made the data obtained with the $A B I$ 373 indistinguishable from those obtained with the ABI 377.

Sequence analysis. Computer analysis was performed using both the Genetics Computer Group (GCG) and Staden software packages. Sequence files were analysed by using the BLAST server at the National Center of Biotechnology Information (Bethesda, MD, USA). The BLASTX program translated each sequence in all six reading frames which were then used to search the non-redundant protein sequence database. Sequences were considered to have given a significant database match when the probability $(P)$ value was $\leqslant 10^{-3}$ and score $\geqslant 100$.

ORF analysis was performed by running the assembled consensus sequences and their complements through the GCG CODONPREFERENCE program using an $R$. sphaeroides codon usage table (J. M. Eraso \& S. Kaplan, unpublished). The codon usage table was derived using the $R$. sphaeroides sequences already available in the NCBI database but did not include sequence derived from the previously described ribosomal rrn operons (Dryden \& Kaplan, 1990). The graphical output from the program was examined and the largest pORF found amongst the six possible frames was used to estimate the maximum coding capacity for each consensus sequence. The shortest length of sequence which we considered to be a pORF was 51 contiguous amino acids. Clearly, this decision was arbitrary and can be reconsidered as additional information becomes available. All consensus sequences were screened for the presence of tRNAs using the program TRNASCAN (Fichant \& Burks, 1991).

\section{RESULTS}

\section{Sequence 'skimming' of the small chromosome}

Subclones were constructed from 23 cosmids containing a total of approximately $417 \mathrm{~kb}$ of unique insert DNA; a summary of the results is shown in Table 1 . Sequencing runs from cosmids 8536 and 8603 generated a lower read length of $300-400$ nucleotides with $1 \%$ ambiguous bases. These formed part of our early sequencing efforts. Adjustment of conditions and an upgrade of the sequencing equipment resulted in $\sim 650-700$ nucleotides of sequence being the norm for the other cosmids. We have observed that $>700$ nucleotides of raw sequence often contained useful data for BLASTX searches, the determination of restriction sites, and fragment assembly.

A total of 944 sequence fragments containing CII DNA was assembled, and a total of 404 sequence contigs was generated. The average gap length was estimated to be $\sim 500$ nucleotides; therefore if required, a large number of gaps could be resolved by primer walking. The total unique DNA sequence was $\sim 291 \mathrm{~kb}$, representing approximately $70 \%$ of the total insert coverage. This coverage represents approximately one-third of the small chromosome of $R$. sphaeroides.

\section{DNA composition and codon usage}

The G + C composition of the R. sphaeroides genome was determined to be $66.0 \mathrm{~mol} \%$. This included 346593 nucleotides of CI and CII sequence obtained from GenBank and this study. In one approach used to determine if $\mathrm{CI}$ and $\mathrm{CII}$ have different evolutionary origins we obtained from GenBank the sequences of protein-coding genes (i.e. no rRNAs or tRNAs) which have been mapped to $\mathrm{CI}$ and compared their overall $\mathrm{mol} \% \mathrm{G}+\mathrm{C}$ content with those sequences which we had generated for CII. The $\mathrm{G}+\mathrm{C}$ content was found to be $67.3 \mathrm{~mol} \%$ and $65.7 \mathrm{~mol} \%$ for CI and CII, respectively. For this analysis we excluded partial se-

Table 1. Summary of the $\mathrm{Cll}$ sequencing project

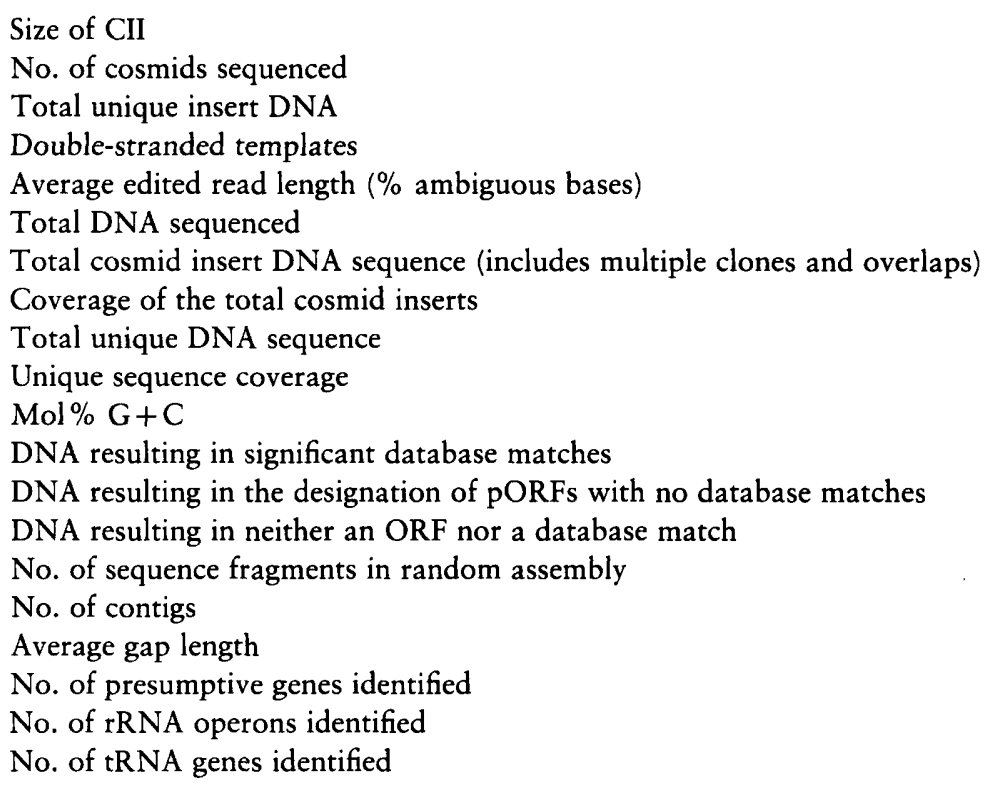

$910 \mathrm{~kb}$
23
$417 \mathrm{~kb}$
573
$559 \pm 268(2 \cdot 8 \%)$
$640 \mathrm{~kb}$
$565 \mathrm{~kb}$
$1 \cdot 3 \times$
$291 \mathrm{~kb}$
$0 \cdot 7 \times$
$65 \cdot 7$
$131 \mathrm{~kb}$
$122 \mathrm{~kb}$
$38 \mathrm{~kb}$
1145
404
$504 \mathrm{bp}$
144
2 (rrnB and $r r n C)$
5 (Ala, Ile, f-Met, Met and Val)


Table 2. Percentages of dinucleotide and trinucleotide repeats

\begin{tabular}{|lrc|}
\hline & CI & CII \\
\hline Dinucleotides & & \\
CG & $13 \cdot 4$ & $13 \cdot 5$ \\
GC & $12 \cdot 7$ & $12 \cdot 0$ \\
GG & $10 \cdot 2$ & $10 \cdot 4$ \\
CC & $9 \cdot 4$ & $9 \cdot 9$ \\
GA & $7 \cdot 2$ & $7 \cdot 1$ \\
TC & $7 \cdot 1$ & $7 \cdot 0$ \\
CT & $5 \cdot 9$ & $6 \cdot 1$ \\
TG & $5 \cdot 8$ & $5 \cdot 2$ \\
CA & $4 \cdot 9$ & $5 \cdot 0$ \\
AG & $4 \cdot 6$ & $4 \cdot 1$ \\
AC & $4 \cdot 4$ & $4 \cdot 2$ \\
AT & $4 \cdot 0$ & $3 \cdot 9$ \\
GT & $3 \cdot 9$ & $3 \cdot 9$ \\
AA & $2 \cdot 9$ & $3 \cdot 3$ \\
TT & $2 \cdot 5$ & $3 \cdot 2$ \\
TA & $1 \cdot 1$ & $1 \cdot 2$ \\
Trinucleotides & & \\
Five most abundant & & \\
CGC & $4 \cdot 6$ & $3 \cdot 9$ \\
GCG & $4 \cdot 6$ & $3 \cdot 8$ \\
GGC & $4 \cdot 3$ & $3 \cdot 6$ \\
CGG & $4 \cdot 0$ & $3 \cdot 7$ \\
CCG & $4 \cdot 0$ & $3 \cdot 6$ \\
Five rarest & & \\
TAG & $0 \cdot 1$ & $0 \cdot 2$ \\
TAA & $0 \cdot 1$ & $0 \cdot 1$ \\
TTA & $0 \cdot 1$ & $0 \cdot 1$ \\
GTA & $0 \cdot 2$ & $0 \cdot 2$ \\
ATA & $0 \cdot 2$ & $0 \cdot 3$ \\
\hline
\end{tabular}

quences obtained from three CII cosmids, 8737, 8503 and 8148 , which contain the $r r n$ operons whose sequence is near $50 \mathrm{~mol} \% \mathrm{G}+\mathrm{C}$ (Dryden \& Kaplan, 1990).

Partial sequence of nine of the twenty cosmids had a lower $\mathrm{G}+\mathrm{C}$ content $(60-62 \mathrm{~mol} \%)$ than the average for CII. These cosmids did not overlap with those cosmids which contained the $r r n$ operons: they were scattered around CII.

In addition, we examined the di- and trinucleotide frequencies of the sequences from both chromosomes; we found that the fraction of each di- or trinucleotide on each of the two chromosomes was approximately equivalent, as shown in Table 2 . We also repeated this process with the $110 \mathrm{~kb}$ replicon for which we have 5790 bp of sequence (P. Sen \& S. Kaplan, unpublished) and again found a similar pattern of rare and frequent di- and trinucleotides as those found on the chromosomes (unpublished observation).

We also examined the codon usage for genes mapping to $\mathrm{CI}$ and $\mathrm{CII}$ which had already been placed in GenBank. Here we looked at the relative fraction of redundant

\section{Table 3. Selective codon usage}

The fraction of each of the redundant codons of Arg, Leu, Ser and Lys found on $\mathrm{CI}$ and $\mathrm{CII}$ is shown. Sample size was $7501 \mathrm{bp}$ and $6890 \mathrm{bp}$ for $\mathrm{CI}$ and CII, respectively.

\begin{tabular}{|llll|}
\hline Amino acid & Codon & CI & CII \\
\hline \multirow{2}{*}{ Arg } & AGG & $0 \cdot 01$ & $0 \cdot 03$ \\
& AGA & $0 \cdot 01$ & $0 \cdot 01$ \\
& CGG & $0 \cdot 24$ & $0 \cdot 25$ \\
& CGA & $0 \cdot 33$ & $0 \cdot 29$ \\
& CGT & $0 \cdot 12$ & $0 \cdot 08$ \\
Leu & CGC & $0 \cdot 29$ & $0 \cdot 34$ \\
& TTG & $0 \cdot 02$ & $0 \cdot 04$ \\
& TTA & $0 \cdot 02$ & $0 \cdot 01$ \\
& CTG & $0 \cdot 31$ & $0 \cdot 35$ \\
& CTA & $0 \cdot 16$ & $0 \cdot 11$ \\
Ser & CTT & $0 \cdot 18$ & $0 \cdot 17$ \\
& CTC & $0 \cdot 31$ & $0 \cdot 32$ \\
& AGT & $0 \cdot 05$ & $0 \cdot 03$ \\
& AGC & $0 \cdot 19$ & $0 \cdot 22$ \\
& TCG & $0 \cdot 36$ & $0 \cdot 14$ \\
& TCA & $0 \cdot 10$ & $0 \cdot 16$ \\
Lys & TCT & $0 \cdot 12$ & $0 \cdot 27$ \\
& TCC & $0 \cdot 17$ & $0 \cdot 18$ \\
Cys & AAG & $0 \cdot 86$ & $0 \cdot 81$ \\
& AAA & $0 \cdot 14$ & $0 \cdot 19$ \\
& TGT & $0 \cdot 25$ & $0 \cdot 27$ \\
& TGC & $0 \cdot 75$ & $0 \cdot 73$ \\
\hline
\end{tabular}

codons for arginine, leucine and serine (see Table 3 ). We found that in general rare codons such as Arg-AGA and Leu-TTA were rare on both chromosomes, whereas relatively frequent codons such as Arg-CGA or LeuCTG were frequent on both chromosomes. This was also true of amino acids specified by fewer redundant codons, such as lysine and cysteine. There were exceptions to this generality, however. For example, Ser-TCG occurs at a frequency of 0.36 on CI but only 0.14 on CII; likewise Ser-TCT occurs at a frequency of 0.12 on CI but 0.27 on CII. Whether these differences represent true differences between the codon usage of the two chromosomes or whether they reflect the relatively small sample sizes (7501 bp and $6890 \mathrm{bp}$ for $\mathrm{CI}$ and CII, respectively) cannot be determined at this time. However, even when these exceptions are included, the overall picture is one of shared codon usage between the two chromosomes.

\section{Analysis of the sequencing strategy}

Libraries representing $\sim 417 \mathrm{~kb}$ unique cosmid insert DNA were generated and used in 1145 sequencing runs. Of these, 944 runs represented cosmid insert DNA, the remainder either $E$. coli or cosmid vector sequences. After assembly these sequences represented $\sim 291 \mathrm{~kb}$ of unique sequence. After analysis, the sequences could be placed into three categories. Of the total unique se- 
Table 4. BLASTX results using the restriction fragment sequences

\begin{tabular}{|c|c|c|c|c|c|c|c|c|c|c|}
\hline No. & $\begin{array}{c}\text { Best } \\
\text { match }\end{array}$ & Cosmid & Gene product or function & $\begin{array}{c}\text { Organism } \\
\text { showing best } \\
\text { match }\end{array}$ & $\begin{array}{l}\text { Sequence } \\
\text { length* }\end{array}$ & $\begin{array}{l}\% \text { of } \\
\text { gene } \\
\text { coveredt }\end{array}$ & $\begin{array}{l}\text { Best hit } \\
\text { sizes }\end{array}$ & $\begin{array}{c}\% \\
\text { identity } \neq\end{array}$ & $\begin{array}{c}\% \\
\text { similarity } \$\end{array}$ & Probability \\
\hline \multirow[t]{2}{*}{1} & bioA & 8207 & Diaminopimelic acid & Rbizobium sp. & 467 & 48 & 84 & 40 & 60 & $3 \cdot 1 \mathrm{e}-45$ \\
\hline & & & aminotransferase & & & & 111 & 30 & 48 & $3 \cdot 1 e-45$ \\
\hline \multirow[t]{2}{*}{2} & redF & 8207 & Integrase & E. coli & 256 & 30 & 36 & 41 & 63 & $3 \cdot 7 e-07$ \\
\hline & & & & & & & 41 & 36 & 51 & $3.7 \mathrm{e}-07$ \\
\hline \multirow[t]{2}{*}{3} & orf & 8207 & Unknown & Mycobacterium & 272 & 92 & 57 & 43 & 52 & $1 \cdot 0 \mathrm{e}-11$ \\
\hline & & & & tuberculosis & & & 65 & 32 & 41 & $1 \cdot 0 \mathrm{e}-11$ \\
\hline \multirow[t]{2}{*}{4} & orf & 8207 & Hypothetical protein & E. coli & 142 & 75 & 39 & 35 & 58 & $5 \cdot 7 \mathrm{e}-13$ \\
\hline & & & & & & & 41 & 31 & 56 & $5 \cdot 7 \mathrm{e}-13$ \\
\hline 5 & $b c s P 31$ & 8207,8737 & $\begin{array}{l}\text { Immunogenic cell surface } \\
\text { protein }\end{array}$ & Brucella abortus & 329 & 79 & 111 & 42 & 60 & $4 \cdot 7 e-32$ \\
\hline 6 & orf & 8207,8737 & Unknown & $\begin{array}{l}\text { Agrobacterium } \\
\text { vitis }\end{array}$ & 324 & 75 & 146 & 56 & 70 & $4 \cdot 4 e-69$ \\
\hline \multirow[t]{2}{*}{7} & bioD & 8737 & Dethiobiotin synthetase 1 & H. influenzae & 242 & 37 & 53 & 50 & 75 & $8 \cdot 5 e-25$ \\
\hline & & & & & & & 37 & 51 & 83 & $8 \cdot 5 e-25$ \\
\hline \multirow[t]{2}{*}{8} & orf & 8737 & Hypothetical protein & Coxiella burnetii & 311 & 61 & 88 & 43 & 63 & $1 \cdot 3 e-50$ \\
\hline & & & & & & & 62 & 50 & 62 & $1 \cdot 3 e-50$ \\
\hline \multirow[t]{2}{*}{9} & orf & 8737 & Unknown & H. influenzae & 508 & 39 & 84 & 78 & 84 & $8.4 \mathrm{e}-97$ \\
\hline & & & & & & & 60 & 63 & 76 & $8 \cdot 4 e-97$ \\
\hline 10 & orf & 8737 & Unknown & Synechocystis sp. & 335 & 32 & 110 & 35 & 55 & $5 \cdot 0 e-16$ \\
\hline 11 & orf 2 & 8737 & $\begin{array}{l}\text { Downstream Orf of } \mathrm{Fe}-\mathrm{S} \\
\text { fumarase }\end{array}$ & $\begin{array}{l}\text { Bacillus } \\
\text { stearothermophilus }\end{array}$ & 265 & 31 & 82 & 30 & 58 & $2.5 \mathrm{e}-09$ \\
\hline 12 & $r r n C$ & 8737,8503 & rRNA & R. sphaeroides & 6163 & 21 & 651 & 96 & 96 & $1 \cdot 1 \mathrm{e}-265$ \\
\hline \multirow[t]{2}{*}{13} & proB & 8503 & $\gamma$-Glutamyl kinase & E. coli & 367 & 45 & 77 & 45 & 61 & $2 \cdot 9 e-17$ \\
\hline & & & & & & & 89 & 43 & 57 & $1.8 \mathrm{e}-19$ \\
\hline \multirow[t]{2}{*}{14} & orf & 8503 & Unknown & Synechocystis sp. & 443 & 25 & 87 & 50 & 67 & $1 \cdot 6 e-31$ \\
\hline & & & & & & & 23 & 56 & 69 & $1 \cdot 6 e-31$ \\
\hline 15 & $c p T a q$ & 8503,8148 & Carboxypeptidase & $\begin{array}{l}\text { Thermus } \\
\text { aquaticus }\end{array}$ & 511 & 10 & 55 & 45 & 58 & $4 \cdot 1 e-10$ \\
\hline 16 & $\operatorname{cox} W$ & 8503,8148 & $\begin{array}{l}\text { Cytochrome oxidase } \\
\text { assembly factor }\end{array}$ & $\begin{array}{l}\text { Saccharomyces } \\
\text { cerevisiae }\end{array}$ & 486 & 60 & 151 & 43 & 66 & $4 \cdot 6 e-64$ \\
\hline 17 & $r p L 21$ & 8503,8148 & 50S ribosomal protein L21 & Bacillus subtilis & 102 & 100 & 84 & 44 & 63 & $4 \cdot 9 e-20$ \\
\hline 18 & orf & 8503,8148 & Hypothetical protein & E. coli & 228 & 60 & 108 & 34 & 57 & $4 \cdot 1 \mathrm{e}-27$ \\
\hline 19 & obg & 8503,8148 & GTP-binding protein & H. influenzae & 390 & 77 & 204 & 56 & 69 & $1 \cdot 2 \mathrm{e}-77$ \\
\hline 20 & proA & 8148 & $\begin{array}{l}\gamma \text {-Glutamyl phosphate } \\
\text { reductase }\end{array}$ & H. influenzae & 417 & 41 & 129 & 34 & 56 & $1.5 \mathrm{e}-23$ \\
\hline 21 & $e c h$ & 8148 & Enoyl-CoA hydratase & $\begin{array}{l}\text { Clostridium } \\
\text { difficile }\end{array}$ & 155 & 65 & 101 & 34 & 51 & $4 \cdot 1 \mathrm{e}-11$ \\
\hline \multirow[t]{2}{*}{22} & $p l s C$ & 8148 & 1-Acyl-sn-glycerol-3- & Neisseria & 255 & 32 & 48 & 52 & 68 & $7 \cdot 4 \mathrm{e}-16$ \\
\hline & & & phosphate acyltransferase & gonorrboeae & & & 34 & 41 & 64 & $7 \cdot 4 e-16$ \\
\hline \multirow[t]{2}{*}{23} & $\operatorname{aepA}$ & 8148 & Regulatory protein & Erwinia & 465 & 28 & 61 & 36 & 54 & $1 \cdot 3 e-10$ \\
\hline & & & & carotovora & & & 34 & 35 & 44 & $1 \cdot 3 e-10$ \\
\hline 24 & orf & 8148 & Unknown & E. coli & 219 & 42 & 93 & 39 & 58 & $1 \cdot 2 \mathrm{e}-35$ \\
\hline 25 & $r r n B$ & 8148,8215 & rRNA & R. sphaeroides & 6565 & 10 & 686 & 96 & 96 & $1 \cdot 3 e-266$ \\
\hline 26 & orfT2 & 8215 & $\begin{array}{l}\text { Transcriptional regulator } \\
\text { in } r d x A 3^{\prime} \text { region }\end{array}$ & R. sphaeroides & 456 & 23 & 108 & 99 & 99 & $2 \cdot 7 e-70$ \\
\hline 27 & $r d x A$ & 8215 & Redox protein & R. sphaeroides & 469 & 47 & 222 & 93 & 94 & $5 \cdot 3 e-161$ \\
\hline 28 & $n m o B$ & 8215 & $\begin{array}{l}\text { Nitrilotriacetate } \\
\text { monooxygenase }\end{array}$ & $\begin{array}{l}\text { Chelatobacter } \\
\text { beintzii }\end{array}$ & 322 & 38 & 122 & 45 & 63 & $3 \cdot 2 \mathrm{e}-30$ \\
\hline 29 & bem $T$ & 8215 & $\begin{array}{l}\text { 5-Aminolaevulinate } \\
\text { synthase }\end{array}$ & R. sphaeroides & 407 & 27 & 112 & 92 & 92 & $2 \cdot 7 e-74$ \\
\hline 30 & orf & 8215 & Unknown & $\begin{array}{l}\text { Agrobacterium } \\
\text { (Ti plasmid) }\end{array}$ & 322 & 40 & 72 & 88 & 93 & $2 \cdot 1 \mathrm{e}-72$ \\
\hline 31 & potB & 8215 & Putrescine transport & E. coli & 226 & 55 & 78 & 46 & 71 & $3 \cdot 4 e-33$ \\
\hline 32 & orf & 8215 & Unknown & $\begin{array}{c}\text { Agrobacterium } \\
\text { (Ti plasmid) }\end{array}$ & 154 & 90 & 76 & 53 & 71 & $9 \cdot 6 e-36$ \\
\hline 33 & orf140 & 8215 & Unknown & Rhizobium sp. & 140 & 73 & 103 & 39 & 56 & $7 \cdot 5 e-22$ \\
\hline 34 & potD & 8215,8519 & Putrescine transport & E. coli & 348 & 40 & 82 & 41 & 52 & $4 \cdot 4 \mathrm{e}-17$ \\
\hline 35 & $o p p D$ & 8215,8519 & Oligopeptide transport & Rhizobium sp. & 335 & 52 & 144 & 49 & 61 & $2 \cdot 9 e-49$ \\
\hline 36 & $d p p B$ & 8519 & Dipeptide transport & E. coli & 306 & 19 & 59 & 32 & 54 & $2 \cdot 6 \mathrm{e}-04$ \\
\hline 37 & $o p p F$ & 8519 & Oligopeptide transport & Rhizobium sp. & 353 & 34 & 70 & 52 & 67 & $1 \cdot 1 \mathrm{e}-37$ \\
\hline 38 & $d p p A$ & 8519 & Dipeptide transport & E. coli & 512 & 17 & 85 & 34 & 56 & $2 \cdot 4 e-11$ \\
\hline \multirow[t]{2}{*}{39} & potC & 8519 & Putrescine transport & H. influenzae & 247 & 40 & 56 & 37 & 67 & $2 \cdot 3 \mathrm{e}-15$ \\
\hline & & & & & & & 34 & 50 & 76 & $2 \cdot 3 e-15$ \\
\hline 40 & potH & 8519 & Putrescine transport & E. coli & 317 & 49 & 77 & 51 & 71 & $1 \cdot 2 e-33$ \\
\hline
\end{tabular}


Table 4. (cont.)

\begin{tabular}{|c|c|c|c|c|c|c|c|c|c|c|}
\hline No. & $\begin{array}{l}\text { Best } \\
\text { match }\end{array}$ & Cosmid & Gene product or function & $\begin{array}{l}\text { Organism } \\
\text { showing best } \\
\text { match }\end{array}$ & $\begin{array}{l}\text { Sequence } \\
\text { length* }\end{array}$ & $\begin{array}{c}\% \text { of } \\
\text { gene } \\
\text { coveredt }\end{array}$ & $\begin{array}{l}\text { Best hit } \\
\text { sizes }\end{array}$ & $\begin{array}{c}\% \\
\text { identitył }\end{array}$ & $\begin{array}{c}\% \\
\text { similarityS }\end{array}$ & Probabilityg \\
\hline \multirow[t]{2}{*}{41} & orf & 8519 & Hypothetical protein & Xanthobacter sp. & 249 & 29 & 35 & 60 & 80 & $2 \cdot 1 e-18$ \\
\hline & & & & & & & 37 & 51 & 64 & $2 \cdot 1 \mathrm{e}-18$ \\
\hline 42 & $d m s A$ & 8519,8508 & DMSO reductase & R. sphaeroides & 822 & 100 & 371 & 95 & 96 & $1 \cdot 3 e-127$ \\
\hline 43 & $d m s B$ & 8519,8508 & DMSO reductase & R. sphaeroides & 53 & 100 & 46 & 86 & 91 & $8 \cdot 2 e-22$ \\
\hline 44 & moeA & 8519,8508 & Molybdopterin synthesis & E. coli & 411 & 53 & 94 & 32 & 55 & $2 \cdot 6 e-41$ \\
\hline 45 & moaA & 8519,8508 & Molybdopterin synthesis & E. coli & 329 & 30 & 99 & 39 & 48 & $2 \cdot 5 e-11$ \\
\hline 46 & $\operatorname{pot} A$ & 8508 & Putrescine transporter & E. coli & 378 & 78 & 143 & 56 & 68 & $7 \cdot 4 e-50$ \\
\hline \multirow{2}{*}{47} & tor $C$ & 8519,8508 & c-type cytochrome & E. coli & 390 & 33 & 61 & 60 & $\pi 7$ & $3 \cdot 2 e-58$ \\
\hline & & & & & & & 44 & 52 & 72 & $3 \cdot 2 e-58$ \\
\hline 48 & $\operatorname{arcB}$ & 8519,8508 & $\begin{array}{l}\text { Aerobic control sensory } \\
\text { kinase }\end{array}$ & E. coli & 776 & 19 & 72 & 43 & 63 & $6 \cdot 4 e-11$ \\
\hline 49 & $\operatorname{yexN}$ & 8519,8508 & Transcriptional regulator & $\begin{array}{l}\text { Aeromonas } \\
\text { salmonicida }\end{array}$ & 193 & 41 & 81 & 40 & 58 & $2 \cdot 9 e-12$ \\
\hline \multirow[t]{2}{*}{50} & $\operatorname{arcA}$ & 8508,8508 & Aerobic respiration & E. coli & 238 & 47 & 57 & 42 & 61 & $1 \cdot 2 \mathrm{e}-16$ \\
\hline & & & control protein & & & & 33 & 45 & 62 & $1 \cdot 2 e-16$ \\
\hline 51 & orf & 8656 & Hypothetical protein & Synechocystis sp. & 332 & 53 & 131 & 35 & 58 & $2 \cdot 2 e-37$ \\
\hline 52 & $q \circ x B$ & 8656 & Quinol oxidase subunit I & B. subtilis & 649 & 22 & 147 & 38 & 63 & $4 \cdot 3 e-37$ \\
\hline 53 & orf & 8656 & Hypothetical protein & E. coli & 98 & 35 & 35 & 54 & 85 & $4 \cdot 5 \mathrm{e}-07$ \\
\hline 54 & $m c p A$ & 8656 & $\begin{array}{l}\text { Methyl-accepting } \\
\text { chemotaxis protein }\end{array}$ & B. subtilis & 661 & 14 & 95 & 33 & 64 & $2 \cdot 6 e-13$ \\
\hline 55 & $\operatorname{dad} A$ & 8656,8318 & $\begin{array}{l}\text { D-Amino acid } \\
\text { dehydrogenase }\end{array}$ & E. coli & 432 & 100 & 136 & 57 & 72 & $7 \cdot 1 \mathrm{e}-50$ \\
\hline 56 & orf & 8318 & Hypothetical protein & Synechocystis sp. & 319 & 55 & 125 & 52 & 71 & $4 \cdot 3 e-60$ \\
\hline 57 & orf & 8318 & Unknown & E. coli & 255 & 50 & 85 & 45 & 67 & $1 \cdot 2 \mathrm{e}-36$ \\
\hline 58 & orf & 8318 & Hypothetical protein & E. coli & 344 & 43 & 82 & 35 & 62 & $1 \cdot 2 e-20$ \\
\hline 59 & orf & 8318 & $\begin{array}{l}\text { Hypothetical } \\
\text { transcriptional } \\
\text { regulator }\end{array}$ & Synechocystis sp. & 295 & 60 & 107 & 36 & 56 & $8 \cdot 9 e-32$ \\
\hline 60 & orf & 8318 & Unknown & Synechocystis sp. & 383 & 26 & 103 & 53 & 68 & $1 \cdot 8 \mathrm{e}-29$ \\
\hline 61 & $\operatorname{ars} G$ & 8318,8790 & Arsenate reductase & E. coli & 141 & 97 & 67 & 47 & 58 & $2 \cdot 2 e-14$ \\
\hline 62 & $y j c G$ & 8790 & $\mathrm{Na}^{+}$symport & E. coli & 549 & 35 & 137 & 65 & 75 & $3 \cdot 0 e-72$ \\
\hline \multirow[t]{2}{*}{63} & yich & 8790 & Unknown & E. coli & 104 & 79 & 53 & 35 & 52 & $1.9 \mathrm{e}-13$ \\
\hline & & & & & & & 30 & 56 & 73 & $1.9 \mathrm{e}-13$ \\
\hline 64 & orf & 8790 & Unknown & $\begin{array}{l}\text { Sulfolobus } \\
\text { acidocaldarius }\end{array}$ & 275 & 44 & 91 & 31 & 52 & $8 \cdot 0 \mathrm{e}-19$ \\
\hline 65 & orf & 8790 & Hypothetical protein & E. coli & 534 & 98 & 156 & 55 & 72 & $5 \cdot 8 e-63$ \\
\hline 66 & orf & 8790 & Transcriptional regulator & H. influenzae & 288 & 61 & 103 & 35 & 53 & $1 \cdot 5 \mathrm{e}-33$ \\
\hline \multirow[t]{2}{*}{67} & orf & 8790 & Unknown & Mycobacterium & 498 & 32 & 68 & 36 & 51 & $3.9 e-16$ \\
\hline & & & & tuberculosis & & & 24 & 50 & 70 & $3.9 e-16$ \\
\hline \multirow[t]{2}{*}{68} & orf & 8790 & Unknown & M. tuberculosis & 431 & 39 & 68 & 38 & 55 & $3 \cdot 8 e-13$ \\
\hline & & & & & & & 38 & 39 & 50 & $3 \cdot 8 \mathrm{e}-13$ \\
\hline 69 & $f a b G$ & 8736 & Ketoacyl-ACP reductase & Vibrio harveyi & 244 & 47 & 89 & 42 & 60 & $5 \cdot 5 e-24$ \\
\hline 70 & $x d h A$ & 8736 & $\begin{array}{l}\text { Hydroxysteroid } \\
\text { dehydrogenase }\end{array}$ & E. coli & 255 & 28 & 73 & 42 & 57 & $1 \cdot 5 e-12$ \\
\hline 71 & $d a p B$ & 8736 & $\begin{array}{l}\text { Dihydrodipicolinate } \\
\text { reductase }\end{array}$ & $\begin{array}{l}\text { Pseudomonas } \\
\text { aeroginosa }\end{array}$ & 216 & 35 & 75 & 32 & 49 & $8.0 \mathrm{e}-06$ \\
\hline 72 & $d f p$ & 8736 & $\begin{array}{l}\text { Flavoprotein } \\
\text { (DNA/pantothenate } \\
\text { metabolism) }\end{array}$ & H. influenzae & 400 & 50 & 120 & 46 & 67 & $9 \cdot 8 e-56$ \\
\hline 73 & $c b i O$ & 8736 & ABC transporter & H. influenzae & 217 & 47 & 103 & 43 & 61 & $7 \cdot 5 e-21$ \\
\hline \multirow[t]{2}{*}{74} & $a p p C$ & 8736 & Acid phosphatase & E. coli & 514 & 22 & 38 & 36 & 63 & $4 \cdot 9 e-20$ \\
\hline & & & & & & & 41 & 34 & 53 & $4 \cdot 9 e-20$ \\
\hline 75 & piaA & 8736 & $\begin{array}{l}\text { Negative transcriptional } \\
\text { regulator }\end{array}$ & B. subtilis & 172 & 43 & 74 & 33 & 56 & $4 \cdot 2 e-09$ \\
\hline 76 & orf & 8736 & Unknown & Synechocystis sp. & 214 & 68 & 79 & 51 & 73 & $3.8 e-25$ \\
\hline 77 & orf & 8736 & Unknown & E. coli & 732 & 25 & 99 & 43 & 59 & $2 \cdot 0 e-42$ \\
\hline 78 & cyoD & 8736 & $\begin{array}{l}\text { Cytochrome oxidase } d \\
\text { subunit II }\end{array}$ & E. coli & 182 & 41 & 74 & 32 & 56 & $1 \cdot 2 \mathrm{e}-06$ \\
\hline 79 & $c y o A$ & 8736,8075 & $\begin{array}{l}\text { Cytochrome oxidase } d \\
\text { subunit I }\end{array}$ & $\begin{array}{l}\text { Halobacterium } \\
\text { salinarium }\end{array}$ & 160 & 91 & 88 & 48 & 71 & $8 \cdot 5 e-46$ \\
\hline \multirow[t]{2}{*}{80} & $\operatorname{sas} A$ & 8075 & Sensory kinase & Synechococcus sp. & 380 & 49 & 62 & 37 & 59 & $1.6 \mathrm{e}-15$ \\
\hline & & & & & & & 87 & 25 & 43 & $1.6 \mathrm{e}-15$ \\
\hline 81 & fat $D$ & 8075 & Iron transporter & B. subtilis & 316 & 100 & 140 & 40 & 74 & $1.7 e-40$ \\
\hline \multirow[t]{2}{*}{$\begin{array}{l}01 \\
82\end{array}$} & $m l t B$ & 8075 & Membrane-bound & E. coli & 361 & 56 & 61 & 32 & 54 & $8 \cdot 5 e-16$ \\
\hline & & & transglycosylase & & & & 39 & 58 & 76 & $8 \cdot 5 e-16$ \\
\hline
\end{tabular}


Table 4. (cont.)

\begin{tabular}{|c|c|c|c|c|c|c|c|c|c|c|}
\hline No. & $\begin{array}{c}\text { Best } \\
\text { match }\end{array}$ & Cosmid & Gene product or function & $\begin{array}{c}\text { Organism } \\
\text { showing best } \\
\text { match }\end{array}$ & $\begin{array}{l}\text { Sequence } \\
\text { length* }\end{array}$ & $\begin{array}{l}\% \text { of } \\
\text { gene } \\
\text { covered } t\end{array}$ & $\begin{array}{l}\text { Best hit } \\
\text { sizes }\end{array}$ & $\begin{array}{c}\% \\
\text { identity } \ddagger\end{array}$ & $\begin{array}{c}\% \\
\text { similarity } \$\end{array}$ & Probability 9 \\
\hline 83 & orf & 8075 & Unknown & $\begin{array}{l}\text { Erwinia } \\
\text { chrysanthemi }\end{array}$ & 132 & 57 & 76 & 43 & 56 & $6 \cdot 5 e-19$ \\
\hline 84 & bluB & 8075 & BluB protein & R. capsulatus & 206 & 82 & 112 & 37 & 47 & $4 \cdot 8 \mathrm{e}-29$ \\
\hline 85 & orf & 8075 & Transducer & P. aeruginosa & 629 & 19 & 85 & 34 & 55 & $2 \cdot 6 \mathrm{e}-08$ \\
\hline \multirow[t]{2}{*}{86} & orf & 8075 & Unknown & E. coli & 279 & 57 & 55 & 61 & 72 & $7 \cdot 0 \mathrm{e}-54$ \\
\hline & & & & & & & 44 & 65 & 75 & $7 \cdot 0 \mathrm{e}-54$ \\
\hline 87 & $d p p A$ & 8075,8025 & Dipeptide transporter & E. coli & 535 & 32 & 124 & 59 & 76 & $4 \cdot 4 e-63$ \\
\hline \multirow[t]{2}{*}{88} & baeS & 8025 & Sensory kinase & E. coli & 466 & 22 & 83 & 27 & 45 & $5 \cdot 8 e-06$ \\
\hline & & & & & & & 20 & 35 & 65 & $5 \cdot 8 e-06$ \\
\hline 89 & $\operatorname{cop} R$ & 8025 & $\begin{array}{l}\text { Transcriptional activator } \\
\text { protein }\end{array}$ & $\begin{array}{l}\text { Pseudomonas } \\
\text { syringae }\end{array}$ & 227 & 54 & 65 & 44 & 60 & $1 \cdot 4 e-32$ \\
\hline 90 & $d p p D$ & 8025 & ATP-binding domain & H. influenzae & 330 & 19 & 65 & 55 & 72 & $1 \cdot 6 \mathrm{e}-17$ \\
\hline 91 & $n i k E$ & 8025 & Nickel transport & E. coli & 268 & 27 & 74 & 43 & 56 & $5 \cdot 3 e-13$ \\
\hline 92 & orf & 8025 & Unknown & E. coli & 370 & 41 & 106 & 62 & 65 & $3 \cdot 6 e-48$ \\
\hline 93 & orf & 8025 & Unknown & E. coli & 179 & 19 & 35 & 65 & 68 & $1.6 e-07$ \\
\hline 94 & dap & 8025,8219 & D-Aminopeptidase & $\begin{array}{l}\text { Ochrobactrum } \\
\text { anthropi }\end{array}$ & 520 & 35 & 115 & 53 & 68 & $6 \cdot 0 e-40$ \\
\hline \multirow[t]{2}{*}{95} & $d p p B$ & 8025,8219 & Dipeptide permease & E. coli & 339 & 95 & 89 & 69 & 83 & $1 \cdot 2 \mathrm{e}-53$ \\
\hline & & & & & & & 113 & 46 & 69 & $1 \cdot 6 e-42$ \\
\hline 96 & $d p p F$ & 8025,8219 & Dipeptide transport & $\begin{array}{l}\text { Salmonella } \\
\text { typhimurium }\end{array}$ & 334 & 50 & 136 & 61 & 81 & $3 \cdot 0 \mathrm{e}-72$ \\
\hline 97 & $c b b M_{\mathrm{II}}$ & 8219 & $\begin{array}{l}\text { Ribulose bisphosphate } \\
\text { carboxylase/oxygenase }\end{array}$ & R. sphaeroides & 459 & 36 & 166 & 100 & 100 & $2 \cdot 9 e-140$ \\
\hline 98 & $c b b A_{\text {II }}$ & 8219 & $\begin{array}{l}\text { Fructose bisphosphate } \\
\text { aldolase }\end{array}$ & R. sphaeroides & 354 & 79 & 281 & 99 & 99 & $1 \cdot 1 \mathrm{e}-233$ \\
\hline 99 & $c b b G_{\mathrm{II}}$ & 8219 & $\begin{array}{l}\text { Glyceraldehyde-3- } \\
\text { phosphate dehydrogenase }\end{array}$ & R. sphaeroides & 333 & 62 & 209 & 96 & 98 & $1 \cdot 2 \mathrm{e}-141$ \\
\hline 100 & $c b b P_{\mathrm{II}}$ & 8219 & Phosphoribulokinase & R. sphaeroides & 292 & 84 & 245 & 99 & 99 & $6.9 \mathrm{e}-177$ \\
\hline 101 & $c b b T_{\mathrm{II}}$ & 8219 & Transketolase & R. sphaeroides & 657 & 17 & 116 & 100 & 100 & $2 \cdot 2 \mathrm{e}-74$ \\
\hline 102 & $c b b F_{\mathrm{II}}$ & 8219 & Fructose bisphosphatase & R. sphaeroides & 331 & 52 & 172 & 99 & 99 & $2 \cdot 0 \mathrm{e}-134$ \\
\hline 103 & $d p p C$ & 8219 & $\begin{array}{l}\text { Dipeptide transport } \\
\text { protein }\end{array}$ & E. coli & 300 & 35 & 107 & 43 & 57 & $6 \cdot 0 \mathrm{e}-25$ \\
\hline 104 & btrA & 8219 & Heat-shock protein & B. abortus & 513 & 14 & 73 & 45 & 63 & $2 \cdot 9 \mathrm{e}-14$ \\
\hline 105 & $a m i C$ & 8219 & $\begin{array}{l}\text { Aliphatic amidase } \\
\text { expression regulating } \\
\text { protein }\end{array}$ & Synechocystis sp. & 446 & 33 & 146 & 37 & 56 & $1 \cdot 3 e-30$ \\
\hline 106 & orf & 8219 & Unknown & R. sphaeroides & 38 & 100 & 38 & 100 & 100 & $6 \cdot 2 e-21$ \\
\hline 107 & act206 & 8536 & Acid inducible & $\begin{array}{l}\text { Rhizobium } \\
\text { (Sinorbizobium) } \\
\text { meliloti }\end{array}$ & 541 & 24 & 56 & 60 & 76 & $4 \cdot 2 e-31$ \\
\hline 108 & $m e t K$ & 8536 & $\begin{array}{l}\text { S-Adenosylmethionine } \\
\text { synthetase }\end{array}$ & E. coli & 383 & 71 & 109 & 59 & 75 & $4 \cdot 8 e-41$ \\
\hline 109 & aroA & 8536 & $\begin{array}{l}\text { 3-Phosphoshikimate } \\
\text { 1-carboxyvinyltransferase }\end{array}$ & Synechocystis sp. & 447 & 40 & 98 & 60 & 68 & $9 \cdot 5 e-98$ \\
\hline 110 & $r p s A$ & 8536 & $\begin{array}{l}\text { 30S ribosomal subunit } \\
\text { proteins }\end{array}$ & $\begin{array}{l}\text { Rhizobium } \\
\text { (Sinorbizobium) } \\
\text { meliloti }\end{array}$ & 568 & 56 & 87 & 79 & 93 & $1.5 \mathrm{e}-52$ \\
\hline 111 & $\operatorname{bim} D$ & 8536 & $\begin{array}{l}\text { Integration host factor } b \\
\text { subunit }\end{array}$ & R. capsulatus & 95 & 71 & 55 & 78 & 85 & $8 \cdot 2 \mathrm{e}-32$ \\
\hline 112 & $\operatorname{trpF}$ & 8536 & Anthranilate isomerase & $\begin{array}{c}\text { Caulobacter } \\
\text { crescentus }\end{array}$ & 219 & 94 & 121 & 40 & 57 & $1 \cdot 5 \mathrm{e}-27$ \\
\hline 113 & $\operatorname{trp} B$ & 8536 & Tryptophan synthase & C. crescentus & 406 & 49 & 122 & 78 & 84 & $6 \cdot 2 e-62$ \\
\hline 114 & $g v p N$ & 8536 & Gas vesicle protein $N$ & $\begin{array}{l}\text { Anabaena } \\
\text { flos-aquae }\end{array}$ & 335 & 30 & 100 & 38 & 50 & $2 \cdot 4 \mathrm{e}-15$ \\
\hline 115 & butH & 8536 & Histidine ammonia lyase & Human & 657 & 16 & 107 & 30 & 44 & $8 \cdot 1 \mathrm{e}-09$ \\
\hline 116 & orf & 8536 & Hypothetical protein & Synechocystis sp. & 134 & 82 & 110 & 49 & 59 & $2 \cdot 1 e-30$ \\
\hline 117 & orf & 8536 & Unknown & M. tuberculosis & 406 & 10 & 39 & 56 & 66 & $9 \cdot 1 \mathrm{e}-07$ \\
\hline 118 & def & 8536 & Unknown & $\begin{array}{l}\text { Arabidopsis } \\
\text { thaliana }\end{array}$ & 717 & 14 & 90 & 64 & 77 & $7 \cdot 4 e-37$ \\
\hline 119 & phoH & 8536,8603 & $\begin{array}{l}\text { Phosphate-starvation- } \\
\text { inducible protein }\end{array}$ & Synechocystis sp. & 328 & 85 & 145 & 57 & 75 & $6 \cdot 6 e-92$ \\
\hline 120 & tlyC & 8536,8603 & Haemolysin & H. influenzae & 299 & 48 & 100 & 41 & 60 & $4 \cdot 8 e-33$ \\
\hline 121 & orf & 8603 & $\mathrm{ABC}$ transporter & E. coli & 228 & 80 & 56 & 66 & 76 & $2.9 e-55$ \\
\hline 122 & orf & 8603 & Hypothetical protein & H. influenzae & 474 & 57 & 61 & 62 & 77 & $8 \cdot 1 \mathrm{e}-54$ \\
\hline 123 & orf & 8603 & Hypothetical protein & H. influenzae & 154 & 44 & 68 & 52 & 73 & $7 \cdot 6 e-23$ \\
\hline
\end{tabular}


Table 4. (cont.)

\begin{tabular}{|c|c|c|c|c|c|c|c|c|c|c|}
\hline No. & $\begin{array}{c}\text { Best } \\
\text { match }\end{array}$ & Cosmid & Gene product or function & $\begin{array}{c}\text { Organism } \\
\text { showing best } \\
\text { match }\end{array}$ & $\begin{array}{l}\text { Sequence } \\
\text { length* }\end{array}$ & $\begin{array}{c}\% \text { of } \\
\text { gene } \\
\text { covered } \dagger\end{array}$ & $\begin{array}{l}\text { Best hit } \\
\text { sizes }\end{array}$ & $\begin{array}{c}\% \\
\text { identity } \neq\end{array}$ & $\begin{array}{c}\% \\
\text { similarity } \$\end{array}$ & Probabilitys \\
\hline 124 & orf & 8603 & Hypothetical protein & H. influenzae & 246 & 40 & 65 & 32 & 52 & $6 \cdot 6 \mathrm{e}-11$ \\
\hline 125 & orf & 8603 & Hypothetical protein & E. coli & 485 & 25 & 91 & 51 & 69 & $5 \cdot 6 \mathrm{e}-37$ \\
\hline 126 & nifR4 & 8603,8621 & $\sigma^{54}$ RNA polymerase & R. capsulatus & 426 & 80 & 104 & 39 & 54 & $7 \cdot 6 e-70$ \\
\hline 127 & orf1 & 8621 & Unknown & R. (S.) meliloti & 180 & 72 & 113 & 30 & 52 & $5 \cdot 6 \mathrm{e}-16$ \\
\hline 128 & groEL & 8621,8064 & GroEL & $\begin{array}{l}\text { Thermophiilic } \\
\text { bacterium PS-3 }\end{array}$ & 538 & 10 & 52 & 53 & 76 & $3 \cdot 2 e-11$ \\
\hline 129 & $n d v B$ & 8621,8064 & $\begin{array}{l}\text { Cyclic } \beta \cdot(1,2) \text {-glucan } \\
\text { biosynthesis }\end{array}$ & R. (S.) meliloti & 2870 & 90 & 181 & 63 & 77 & $1 \cdot 7 \mathrm{e}-152$ \\
\hline 130 & $c s p B$ & 8064 & Cold-shock-like protein & E. coli & 71 & 88 & 63 & 44 & 60 & $2 \cdot 3 e-13$ \\
\hline 131 & $\operatorname{dct} P$ & 8591 & $\begin{array}{l}\mathrm{C}_{4} \text { dicarboxylase binding } \\
\text { protein }\end{array}$ & R. capsulatus & 333 & 31 & 60 & 31 & 48 & $1 \cdot 6 \mathrm{e}-06$ \\
\hline 132 & $I S V-A 2$ & 8591 & Transposase & $\begin{array}{l}\text { Vibrio } \\
\text { anguillarum }\end{array}$ & 306 & 22 & 34 & 52 & 70 & $5 \cdot 1 \mathrm{e}-11$ \\
\hline 133 & lasR & 8591 & Transcription factor & $P$. aeruginosa & 239 & 43 & 45 & 40 & 60 & $5 \cdot 6 \mathrm{e}-09$ \\
\hline 134 & orf & 8178 & Unknown & M. tuberculosis & 431 & 31 & 57 & 56 & 61 & $2 \cdot 7 \mathrm{e}-26$ \\
\hline 135 & orf & 8324 & Unknown & E. coli & 114 & 81 & 62 & 48 & 67 & $1 \cdot 6 \mathrm{e}-25$ \\
\hline 136 & exollI & 8324 & Exonuclease III & Synechocystis sp. & 275 & 41 & 47 & 59 & 68 & $6 \cdot 0 e-27$ \\
\hline 137 & orf & 8324 & Unknown & $\begin{array}{l}\text { Pseudomonas } \\
\text { carboxydovorans }\end{array}$ & 295 & 64 & 83 & 36 & 49 & $1 \cdot 3 e-11$ \\
\hline 138 & $g p c$ & 8324 & Minor capsid protein-C & Lambda phage & 439 & 23 & 101 & 41 & 56 & $3.5 e-18$ \\
\hline 139 & $g p 5$ & 8324 & Preconnector protein $\mathrm{gp} 5$ & Lambda phage & 501 & 19 & 97 & 44 & 57 & $1 \cdot 3 e-18$ \\
\hline 140 & XorllM & 8721 & DNA methylase & $\begin{array}{l}\text { Xanthomonas } \\
\text { oryzae }\end{array}$ & 424 & 50 & 122 & 66 & 74 & $3 \cdot 1 e-83$ \\
\hline 141 & $\nu s r-d c m$ & 8780 & Very-short patch repair & $\begin{array}{l}\text { Xanthomonas } \\
\text { oryzae }\end{array}$ & 136 & 83 & 84 & 53 & 66 & $5 \cdot 3 e-38$ \\
\hline 142 & cepS & 8780 & $\beta$-Lactamase & Aeromonas sobria & 382 & 62 & 59 & 45 & 62 & $4 \cdot 5 e-55$ \\
\hline 143 & $a m p R$ & 8780 & Amp regulator & R. capsulatus & 289 & 26 & 52 & 76 & 86 & $1 \cdot 1 \mathrm{e}-22$ \\
\hline 144 & $r b s C$ & 8780 & Ribose transport protein & E. coli & 321 & 19 & 60 & 33 & 63 & $4 \cdot 5 \mathrm{e}-05$ \\
\hline 145 & aldH & 8780 & Aldehyde dehydrogenase & E. coli & 519 & 49 & 54 & 61 & 79 & $5 \cdot 2 e-46$ \\
\hline 146 & $\operatorname{sodH}$ & 8780 & $\begin{array}{l}\text { L-Sorbosone } \\
\text { dehydrogenase }\end{array}$ & $\begin{array}{l}\text { Gluconobacter } \\
\text { oxidans }\end{array}$ & 498 & 26 & 69 & 44 & 66 & $3 \cdot 0 e-26$ \\
\hline
\end{tabular}

* The length of the complete subject polypeptide or rRNA, expressed as amino acids or (in the case of rRNA) nucleotides, found in the BLAST search.

†This percentage is an estimate. It is derived from the amount of sequence we have for the proposed homologous $R$. sphaeroides gene as a proportion of the gene found in the database search. The assumption was made that the two genes were the same size.

$\ddagger$ Percentage of $R$. sphaeroides amino acids which are identical to those within the region of homology of the protein, except the cases of $r r n$ operons, where the identity is expressed as a percentage of the homologous nucleotide region.

\$Sum of R. sphaeroides amino acids which are identical and similar, expressed as a percentage of the total number of amino acids or nucleotides found within the region of homology.

I The probability computed by the BLASTX program that sequences found during the search matched by chance.

quence, $\sim 131 \mathrm{~kb}$ DNA $(45 \%)$ gave matches, $P \leqslant 10^{-3}$ and score $\geqslant 100$, to either genes or ORFs (dORFs) in the database. The remaining $\sim 160 \mathrm{~kb}$ DNA $(55 \%)$ of unique sequence did not give database matches. When this latter sequence was analysed using the CODONPREFERENCE program, $122 \mathrm{~kb}(42 \%)$ was estimated to consist of pORFs. These varied from $\geqslant 50$ to 400 amino acid residues in length (the shortest stretch of sequence which we arbitrarily grouped as a pORF was 50 contiguous amino acids). Due to the fragmentary nature of these data, we have not made any attempt to estimate the number of pORFs. Rather we have presented only the fraction of the sequence which we consider may be coding, but which did not give a database match.

The remaining $38 \mathrm{~kb}(13 \%)$ of unique sequence, we believe, is made up of two components, intergenic noncoding sequence and sequence presently encoding puta- tive products of less than 50 amino acid residues. The latter sequences were too short to fall into our definition of a pORF. However, we cannot rule out the possibility that smaller proteins, not showing similarities to known proteins from other organisms, have been missed in our analysis. Also these sequences may subsequently merge with existing gaps to generate recognizable ORFs. Therefore, in this respect we have probably overestimated the fraction of non-coding DNA; this reflects an intrinsic problem with the approach used here.

Considering these limitations we have estimated that CII of $R$. sphaeroides has a coding capacity of at least $\sim 87 \%$ of its DNA, which is in keeping with the level described for other bacterial chromosomes. However, we did note that the number of gene matches was not equally distributed over CII and declined in regions where the $\mathrm{mol} \% \mathrm{G}+\mathrm{C}$ was lower than the average. 


\section{A variety of gene functions map to Cll}

Analysis of the coding sequences resulted in the identification of 144 putative genes representing a wide variety of functions. A list of these genes, with their putative functions and levels of homology, is given in Table 4. The gene numbers in the table are cited in the text as $(n n n)$. Possible roles have been assigned to $72 \%$ of the total of the 144 presumptive genes identified on CII; the remaining $28 \%$ of the genes were assigned as dORFs. In addition to putative protein-coding genes we have also identified tRNAs for valine (cosmid 8207) and methionine (cosmid 8603) and confirmed the position of tRNAs for formylmethionine, alanine and isoleucine and ribosomal RNAs $r r n B^{(25)}$ and $r r n C^{(12)}$ to cosmid 8737.

Presumptive genes were placed into functional classes, for example: protein synthesis - ribosomal proteins $\mathrm{S} 1^{(110)}(r p s A)$ and $\mathrm{L} 21^{(17)} \quad(r p L 21) ;$ amino acid biosynthesis - $S$-adenosylmethionine synthetase ${ }^{(108)}$ (metK), tryptophan synthetase ${ }^{(113)}(\operatorname{trpB})$, 3-phosphoshikimate 1-carboxyvinyltransferase ${ }^{(109)}$ (aroA); fatty acid metabolism - 1-acyl-sn-glycerol-3-phosphate acyltransferase ${ }^{(22)}\left(p l_{s} C\right)$, ketoacyl-ACP reductase ${ }^{(69)}$ $(f a b G)$; transcriptional regulation - pia $A^{(75)}, \operatorname{cop} R^{(89)}$, $\operatorname{arc} A^{(50)}$, amiC $C^{(105)}$; energy metabolism - cytochrome oxidase assembly factor ${ }^{(16)}(\operatorname{cox} \mathrm{W}), c$-type cytochro$\mathrm{me}^{(47)}$ (cytC like), quinol oxidase ${ }^{(52)}$ (qoxB); and structural components - murein hydrolase ${ }^{(82)}(m l t B)$. The genes groEL (K. Nereng \& S. Kaplan, unpublished; Lee et al., 1997) and rpoN or nifR4 (Meijer \& Tabita, 1992), which had previously been mapped to CI, were also found duplicated on $\mathrm{CII}^{(128,126)}$.

It is beyond the scope of this paper to describe the function of each gene listed in Table 4, but some genes have attracted our attention. The gene tentatively identified as encoding ribosomal protein $S 1^{(110)}$ shows exceedingly high homology at the amino acid sequence level to other S1 proteins (Schnier et al., 1988). Interestingly, the $r p s A$ gene product (30S S1 ribosomal protein), which is a part of the translation apparatus, appears to be present as a single copy on CII when surveyed under low-stringency hybridization conditions (C. Mackenzie \& S. Kaplan, unpublished).

Additionally, several genes seem to be important or even essential when considering the structure of the bacterial cell. For example, the gene $m$ mlt $^{(82)}$ encodes the enzyme murein hydrolase (Ehlert et al., 1995), whose proposed role is as a pacemaker enzyme for murein enlargement or as a hydrolase enzyme during the cell division process involving cell septum formation. The involvement in murein metabolism is significant as it gives both mechanical stability and shape to the bacterium.

Regulatory genes represent $\sim 12.5 \%$ of the total genes presently localized on CII. These regulators, e.g. $a e p A^{(23)}$, yex $N^{(49)}, p i a A^{(75)}, a m i C^{(105)}$ and $a m p R^{(143)}$, seem to mediate various positive and negative transcriptional controls. Also, CII includes genes encoding a number of regulatory proteins involving two-component regulatory systems, namely sensory kinases $\left(a r c B^{(48)}, s a s A^{(80)}\right.$ and $\left.b a e S^{(88)}\right)$ and response regulators $\left(\operatorname{arc} A^{(50)}\right.$ and $\left.\operatorname{cop} R^{(89)}\right)$.

In Gram-negative bacteria, small-molecule transport systems have been divided into several classes. One of these, constituting the osmotic shock-sensitive transport system, is responsible for the uptake of a wide range of small molecules including amino acids, sugars, vitamins and ions (Ames, 1986). Approximately $13 \%$ of the total genes identified on CII of $R$. sphaeroides represent transport systems, i.e. dipeptide transport ${ }^{(87,95,103,90,96)}$ $(d p p A, B, C, D, F), \quad$ oligopeptide transport ${ }^{(35,37)}$ $(o p p D, F)$, putrescine/spermidine transport ${ }^{(46,31,39,34,40)}$ (pot $A, B, C, D, H), \mathrm{Na}^{+}$symport $^{(62)}$, iron transport ${ }^{(81)}$ $(f a t D), \mathrm{C}_{4}$ dicarboxylase transport ${ }^{(131)}(\operatorname{dct} P)$ and the ribose transport protein ${ }^{(144)}$ ( $r b s C$ ).

Besides the expected metabolic and biosynthetic functions reported in Table 4, CII contains sequences which encode functions we consider unusual for this photosynthetic organism. We found database matches to $t l y C^{(120)}$, a gene encoding a haemolysin, and $n d v B^{(129)}$, a gene implicated in Rbizobium root nodule development in alfalfa. In the case of $n d v B$, we have now sequenced $90 \%$ of this gene, which encodes a 2870 amino acid polypeptide, the largest protein revealed on CII to date. These findings were unanticipated, as $R$. sphaeroides has not been considered to be an animal pathogen nor a plant symbiont. Further analysis of these genes is currently under way.

\section{Comparison to other bacterial genomes}

We have compared the relative percentages of functional classes of genes on CII to the chromosomes of $E$. coli (Riley, 1993), Haemophilus influenzae Rd (Fleischmann et al., 1995), Methanococcus jannaschii (Bult et al., 1996), Mycoplasma pneumoniae (Himmelreich et al., 1996), and Mycoplasma genitalium (Fraser et al., 1995); see Table 5. CII of $R$. sphaeroides $2.4 .1^{\mathrm{T}}$ encodes a diverse set of functions. Some of these functions, i.e. cellular processes, biosynthesis of small molecules and intermediary metabolism, are found at approximately the same proportion as in other bacterial chromosomes. However, gene functions classified as involved in macromolecular synthesis (transcription and translation) and cell structure are under-represented, whereas regulatory functions are over-represented on CII when compared to other microbial genomes. Whether this is a true reflection of the composition of CII or an artifact of the regions which we have so far examined will require a complete analysis of the chromosome. Approximately $44 \%$ of the total coding DNA (i.e. total unique DNA minus DNA presently classified as 'intergenic' DNA) remains as unassigned pORF DNA. This suggests that even with the large number of genome sequencing projects (Bult et al., 1996; Fleischmann et al., 1995) which have been deposited in the NCBI database there are still many sequences which are unique to $\mathrm{CII}$ of this organism and may reflect the ecological diversity of the members of the genus Rhodobacter.

In the absence of a single contiguous sequence, it was 
Table 5. Comparison of gene-encoded functions in different bacterial species

A comparison of percentage gene content in $R$. sphaeroides, E. coli, Haemophilus influenzae, Methanococcus jannaschii, Mycoplasma pneumoniae and Mycoplasma genitalium, sorted by biological function. The sample size of $R$. sphaeroides genes is 144 , compared with 1717 (E. coli), 1743 (H. influenzae), 1738 (M. jannaschii), 643 (M. pneumoniae) and 470 (M. genitalium). NA, Not applicable.

\begin{tabular}{|c|c|c|c|c|c|c|}
\hline Metabolic pathway & $\begin{array}{l}\text { R. sphaeroides } \\
\text { (CII) }\end{array}$ & E. coli & H. influenzae & M. jannaschii & M. pneumoniae & M. genitalium \\
\hline $\begin{array}{l}\text { I. Intermediary } \\
\text { metabolism }\end{array}$ & $28 \cdot 1$ & 22.6 & $19 \cdot 7$ & $26 \cdot 3$ & 9.5 & 13.8 \\
\hline $\begin{array}{l}\text { Central intermediary } \\
\text { metabolism }\end{array}$ & $9 \cdot 4$ & $13 \cdot 8$ & $3 \cdot 0$ & $5 \cdot 2$ & $1 \cdot 1$ & 1.9 \\
\hline Energy metabolism & $6 \cdot 2$ & $6 \cdot 2$ & $10 \cdot 4$ & $20 \cdot 0$ & $7 \cdot 0$ & $9 \cdot 7$ \\
\hline Regulatory functions & $12 \cdot 5$ & $2 \cdot 6$ & $6 \cdot 3$ & $1 \cdot 1$ & $1 \cdot 4$ & $2 \cdot 2$ \\
\hline $\begin{array}{l}\text { II. Biosynthesis of small } \\
\text { molecules }\end{array}$ & 11.8 & $19 \cdot 1$ & 20.0 & 24.7 & $6 \cdot 3$ & 9.8 \\
\hline Amino acid biosynthesis & $4 \cdot 4$ & 7.6 & 6.8 & $10 \cdot 2$ & 0.0 & $0 \cdot 3$ \\
\hline Biosynthesis of cofactors & 3.7 & 4.9 & $5 \cdot 4$ & $7 \cdot 4$ & 1.5 & 1.6 \\
\hline $\begin{array}{l}\text { Fatty acid and } \\
\text { phospholipid metabolism }\end{array}$ & $3 \cdot 7$ & $2 \cdot 2$ & $2 \cdot 5$ & $1 \cdot 3$ & $1 \cdot 6$ & $1 \cdot 9$ \\
\hline $\begin{array}{l}\text { Purines, pyrimidines, } \\
\text { nucleosides and } \\
\text { nucleotides }\end{array}$ & $0 \cdot 0$ & $4 \cdot 4$ & $5 \cdot 3$ & $5 \cdot 8$ & $3 \cdot 2$ & $6 \cdot 0$ \\
\hline $\begin{array}{l}\text { III. Macromolecule } \\
\text { metabolism }\end{array}$ & 6.8 & $21 \cdot 4$ & $25 \cdot 3$ & $26 \cdot 8$ & 28.4 & 45.6 \\
\hline Replication & $4 \cdot 4$ & $6 \cdot 0$ & $8 \cdot 6$ & 5.9 & $8 \cdot 2$ & $10 \cdot 0$ \\
\hline Transcription & 0.6 & $1 \cdot 4$ & $2 \cdot 7$ & $2 \cdot 9$ & $2 \cdot 3$ & $3 \cdot 8$ \\
\hline Translation & $1 \cdot 8$ & $14 \cdot 0$ & $14 \cdot 0$ & $18 \cdot 0$ & $17 \cdot 9$ & $31 \cdot 8$ \\
\hline IV. Cell structure & 0.6 & 8.5 & $8 \cdot 3$ & 3.8 & $9 \cdot 6$ & $5 \cdot 3$ \\
\hline V. Cellular processes & $18 \cdot 0$ & $18 \cdot 3$ & 17.5 & 14.7 & $11 \cdot 4$ & $17 \cdot 3$ \\
\hline Cellular processes & 3.7 & $5 \cdot 3$ & $5 \cdot 3$ & $5 \cdot 2$ & 3.6 & $6 \cdot 6$ \\
\hline $\begin{array}{l}\text { Transport and binding } \\
\text { protein }\end{array}$ & $14 \cdot 3$ & $13 \cdot 0$ & $12 \cdot 2$ & $9 \cdot 5$ & $7 \cdot 8$ & $10 \cdot 7$ \\
\hline VI. Other categories & $28 \cdot 0$ & 9.8 & $9 \cdot 2$ & 3.6 & $34 \cdot 2$ & $8 \cdot 2$ \\
\hline Unassigned & $44 \cdot 0$ & NA & $42 \cdot 0$ & 62.0 & 9.9 & $32 \cdot 0$ \\
\hline
\end{tabular}

difficult to construct a precise genetic map from our database matches. Nonetheless, we found a number of genes on CII linked in a manner found in other bacterial species. For example, two genes, $\operatorname{pro} A^{(20)}(\gamma$-glutamyl phosphate reductase) and proB $B^{(13)}$ ( $\gamma$-glutamyl kinase) were linked on the overlapping region of cosmids 8503 and 8148. These two genes are also found linked in the distantly related genera $E$. coli (Deutch et al., 1984), Serratia marcescens (Omori et al., 1991), and Thermus thermophilus (Kosuge et al., 1994). In addition aro $A^{(109)}$, $r p s A^{(110)}$ and himD ${ }^{(111)}$ are in this order on CII. This order is also found in E. coli. However, in H. influenzae (Fleischmann et al., 1995) $r p s A^{(110)}$ and himD ${ }^{(111)}$ are linked in this way, but aro $A^{(109)}$ is located elsewhere on the genome. Also $r p L 21^{(17)}$ and $o b g^{(19)}$ were linked on CII of $R$. sphaeroides, and found to be conserved in that organization in H. influenzae (Fleischmann et al., 1995). The genes groEL ${ }^{(128)}$ and rpoN (nifR4)(126), which are linked in Rhizobium (Sinorhizobium) meliloti (Ogawa $\&$ Long, 1995) are also linked in CII of $R$. sphaeroides.
We have fully sequenced the DMSO reductase genes $d m s C B A^{(47,43,42)}$ and have found them to be linked as in a close relative of $R$. sphaeroides, namely Rhodobacter capsulatus (A. McEwan, personal communication). However, the detailed organization of other genes is quite different in the same DMSO-reductase-linked region. For example, $R$. sphaeroides has only two genes involved in molybdenum cofactor biosynthesis $\left(m o e A^{(44)}\right.$ and $m o a A^{(45)}$ ) compared to $R$. capsulatus, which contained at least four genes (moaA, moaD, moe $B$ and moaC). Interestingly, five genes located in a $34 \mathrm{~kb}$ region of an $R$. (S.) meliloti replicon are also found on CII, i.e. oppD $D^{(35)}$, opp $F^{(37)}, b i o A^{(1)}, d c t^{(131)}$ and $f a b G^{(69)}$; however, the positions of these genes are not in the same order as found in $R$. (S.) meliloti (Freiberg et al., 1996). Thus we found some local conservation of linkage involving several genes found in various genera. However, when we examined fragments linked to the same regions, no conservation of linkage relationships at a more distant level between species was found. 
At a more global level the genes encoding proteins involved in tryptophan metabolism appear to be dispersed to both CI and CII (Mackenzie et al., 1995). These earlier results suggested that a subset of these genes was present on CII (Choudhary et al., 1994) and our analysis here indicates this to be the case.

\section{DISCUSSION}

\section{Sequence strategies and genome analysis}

Several bacterial genomes have been either completely sequenced (Fleischmann et al., 1995; Fraser et al., 1995; Bult et al., 1996; Himmelreich et al., 1996) or are currently in the process of being sequenced (Glaser $e t$ al., 1993; Sensen et al., 1996). Two main sequencing strategies have been used in these projects: the sequencing of large numbers of random subclones followed by computer assembly (Haemophilus influenzae and Methanococcus jannaschii), or a directed primer walking approach (Mycobacterium tuberculosis). However, both of these methods have high costs because they involve either severalfold (6 to 10 times) genome coverage, or the requirement for large numbers of primers and other materials to give finished 'baseperfect' sequence.

We have used a low-redundancy, semi-random approach to partially sequence CII of $R$. sphaeroides, the aim being to generate the maximum amount of biological information for the lowest possible cost. Our aim was not to generate a base-by-base account of CII, but rather to generate an overview of the types of genes encoded by CII. We hoped that this approach might allow us to: (i) determine if this replicon encodes a specialized set of function(s), (ii) assess the relationship of this form of genome organization to that routinely observed in other bacteria, (iii) establish a paradigm with which to compare other bacteria having more than one chromosome, and (iv) ascertain if such a genomic organization served as a precursor to the diploid eukaryotes.

From a technical perspective we also wanted to determine how much information could actually be obtained by using a low-redundancy sequencing approach. Those few genomes which have been sequenced to 'perfection' have provided us with many insights into the bacterial and archaeobacterial kingdoms, but perhaps numerous bacterial genomes sequenced to low redundancy could be equally informative both to workers interested in these organisms and from a genetic diversity perspective.

We found that when restriction enzymes recognizing $6 \mathrm{bp}$ were used to generate template subclones, for the most part, an even distribution of sequence data was obtained from each cosmid. These sequences when used in BLAST searches allowed us to determine which genes may be encoded in a particular cosmid, as shown in Table 4. However, these sequences also allowed us to deduce the potential genetic content of each cosmid by a process of extrapolation. For example, if $300 \mathrm{bp}$ at one end of a subclone matched a region of a gene which in toto encoded a 400 amino acid residue polypeptide, we could extrapolate the size of our partially sequenced gene to be $1200 \mathrm{bp}$. Therefore with only $300 \mathrm{bp}$ of sequence we could account for $1200 \mathrm{bp}$ of cosmid sequence. As the ends of restriction fragment which gave BLAST hits to the same gene could be abutted and assembled by computer, low-resolution genetic maps could be generated. These fragments of sequence information have allowed us to focus on particular genes of interest which we did not know existed in this organism until the cosmids were sequenced. In the case of the DMSO reductase, an initial $700 \mathrm{bp}$ of sequence gave us an indication of the presence of these genes. This has led to the acquisition of their complete sequence and the functional study of their products (N. J. Mouncey, M. Choudhary \& S. Kaplan, unpublished). Such genes of interest can be readily subcloned either by using the correct combination of restriction fragments, or by PCR. In both approaches the information required for subcloning had been generated by the low-redundancy approach.

\section{Multiple chromosomes and gene duplication in prokaryotes}

Genome sizes vary greatly among micro-organisms (Krawiec \& Riley, 1990). Within a single taxonomic group or even within a single species, considerable levels of genome plasticity have been observed (Fonstein \& Haselkorn, 1995). A number of reports have appeared describing several bacterial species possessing more than one chromosome (Michaux et al., 1993; Zuerner et al., 1993; Allardet-Servent et al., 1993; Cheng \& Lessie, 1994). In addition, linear rather than circular chromosomes have also been described in Streptomyces sp. (Lin et al., 1993), Borrelia (Ferdows \& Barbour, 1989), and Agrobacterium (Allardet-Servent et al., 1993). Also some bacterial species of the genera Pseudomonas (Frantz $\&$ Chakrabarty, 1986), Rhizobium (Sobral et al., 1991), and Alcaligenes (Rodley et al., 1995) harbour very large accessory genetic elements (megaplasmids) which appear to encode 'housekeeping' functions (Finan et al., 1986; Pardo et al., 1994); however their 'essentiality' has not been demonstrated. These findings raise the question: what, if anything, defines a bacterial chromosome? Is it the possession of an rrn operon, is it size, topology, the possession of essential genes or any combination of these? Thus, we would propose for bacteria possessing complex genomes that the definition of a chromosome can only be considered in the context of the total genome, i.e. the distribution of genetic elements between the linkage groups.

We have shown previously that transposon insertions mapping to $\mathrm{CII}$ can generate auxotrophic phenotypes (Choudhary et al., 1994), suggesting that genes essential for the day-to-day survival of $R$. sphaeroides are carried on CII. We have also shown the presence on CII of two rRNA operons and a number of tRNAs (Dryden \& Kaplan, 1990). In addition, our sequencing has shown 
that there are numerous genes carried on CII which have already been found on the single chromosomes of $E$. coli, $H$. influenzae, M. tuberculosis and others.

When considered in toto, the data reported here confirm the designation of each major linkage group in $R$. sphaeroides 2.4 .1 as a chromosome. Although not yet completed, the low-resolution DNA sequencing of CII confirms the existence of all major groups of genes as applied to the analysis of those genomes sequenced in their entirety. Further, unlike the recently reported sequence of the rhizobial plasmid (Freiberg et al., 1997) which in addition to lacking several of the major gene groupings, such as macromolecular biosynthesis, cell structure and intermediary metabolism reported here, contains sets of genes associated with a more dedicated lifestyle, i.e. nodulation, CII contains no discernible clusters of genes dedicated to a specific lifestyle or physiological state. In many respects, and granting the still limited level of analysis, CII is indistinguishable from the classical single, circular bacterial chromosome encoding a wide range of biological functions and as such must be considered essential in that broad context.

Here, for example, we have considered those genes encoding enzymes involved in tryptophan metabolism as essential, yet the same genes are absent from the Mycoplasma pneumoniae genome (Himmelreich et al., 1996) and probably from the human genome. From this we could conclude that it is the amino acid L-tryptophan which is essential and not the genes. However, since $R$. sphaeroides or E. coli normally (the wild-type phenotype) make their own L-tryptophan, then in this narrow context, these genes are essential in our description of this organism. On the other hand the presence of a single $r p s A$ gene on the small chromosome requires very little further definition of essentiality.

A growing number of gene homologues have been identified in $R$. sphaeroides with one member of each pair located on each chromosome. We have found additional pairs of homologues, such as rpoN, groEL, hul and hip duplicated either between the large and small chromosomes or between the large chromosome and a $110 \mathrm{~kb}$ replicon. Nonetheless, the physiological role(s) of many of these gene homologues have not yet been demonstrated (Krawiec \& Riley, 1990; Labedan \& Riley, 1995). Recent results (J. Zielstra-Ryalls \& S. Kaplan, unpublished) involving the hemA and hem $T$ gene pair of $R$. sphaeroides have now revealed that the bem $T$ gene is likely to be transcribed by use of the $r p o E$ encoded sigma factor and hemA by RpoD. Thus, the presence of two genes encoding the same function has added an element of metabolic diversity and perhaps an increased level of adaptability to this organism.

Often when a gene is duplicated, one of the two copies may diverge in function to the point where these remain only remotely reminiscent of such a relationship or one copy may become nonfunctional. It is also possible, however, that these duplicated copies may retain their obvious identities but divergence might occur at the level of gene regulation and expression, which could reflect an increased adaptability. Because of its genome structure and the clear presence of partial diploidy, $R$. sphaeroides may serve as a model system to study the origin and evolution of diploidy and of complex bacterial genomes.

This raises the question as to the evolutionary origin of CII. Did it arise by the disruption of a single large chromosome into two smaller chromosomes, was it acquired from some other organism, or was one of these two 'built' as the result of abnormal chromosomal segregation and gradual gene reassortment? In Rhizobium (Sinorhizobium) meliloti the $500 \mathrm{~kb}$ megaplasmid encodes a number of genes (Freiberg et al., 1996) such as bio $A$ and $f a b G$ which would normally be considered chromosomal. However, the lower $\mathrm{G}+\mathrm{C}$ content of the genes on this megaplasmid versus the chromosome suggests that these genes, if not the megaplasmid itself, were acquired by horizontal transfer (Freiberg et al., 1996, 1997).

The virtually identical $\mathrm{G}+\mathrm{C}$ content, di- and trinucleotide frequencies and occurrence of rare codons existing between $\mathrm{CI}$ and $\mathrm{CII}$ suggest that $\mathrm{CII}$ was not derived exogenously. Therefore we do not have any evidence to support the hypothesis that CII was acquired by horizontal transfer from another organism. We found a similar situation when we examined the limited sequence which was available from the $R$. sphaeroides $110 \mathrm{~kb}$ replicon, which also appears to contain a growing list of essential genes (P. Sen, $K$. Nereng \& $S$. Kaplan, unpublished). This suggests that CI, CII and perhaps the $110 \mathrm{~kb}$ replicon may have arisen either from a single larger replicon or have been constructed de novo by the reassortment of existing DNA sequence. If both CI and CII were derived from a larger 'mother' chromosome, then the genetic content of each chromosome would merely reflect the event which gave rise to the dissolution of the 'mother' chromosome. There is no reason to believe that such an event should have partitioned the various gene groupings in proportion to their overall occurrence on the 'mother' chromosome. Suppose that CII was constructed de novo from portions of the 'mother' chromosome and acquired, over time, its present display of genes. Then, there is also no reason to suggest that the acquisition of genetic elements should have occurred in proportion to their presence on the 'mother' chromosome. Therefore it is essential when considering the genetic content of those prokaryotes possessing more than a single chromosome, that the occurrence of various gene groupings reflects the genetic content of the total genome and not that each individual chromosome has to resemble the model bacterial chromosome. Such a concept would certainly be intuitive if we were discussing the genome of eukaryotic systems. Thus, detailed DNA sequence comparisons between $R$. sphaeroides, $R$. capsulatus and other members of the $\alpha-3$ subgroup of the Proteobacteria should shed light on the origin of genome complexity in these bacteria. 


\section{Origin and evolution of the mitochondrial system}

Although the data presented in this study have little direct bearing on the origin of the mitochondria, previous studies raised the likelihood that members of the $\alpha-3$ subdivision of the Proteobacteria were the progenitors of the primitive mitochondrial system (Woese et al., 1984; Yang et al., 1985). It has also been postulated that the mitochondrial system originated through the reductive evolution of an early endosymbiont by reducing its genome size over time and subsequent loss of numerous genes from the 'evolving' mitochondrial genome. Many of these genes, however, may have become part of the host genome, where today they provide much of the observed nuclear/mitochondrial interaction. This original endosymbiont could have evolved in several different ways, ultimately existing as a pathogen (e.g. rickettsiae), or as a free-living symbiont (e.g. rhizobia), or as a benign mitochondrion. It can be envisioned that the presence of multiple chromosomes was significant in the development of these latter relationships. Thus, the endosymbiont could undergo genetic partitioning with its host organism without completely surrendering its genetic identity and autonomy through the assortment and reassortment of genetic information present on multiple chromosomes. Therefore, studies of genomic organization and gene structure and function among members of the Proteobacteria could further refine our knowledge and help to resolve the questions of both the ancestry and the mechanism of mitochondrial origin.

\section{ACKNOWLEDGEMENTS}

We thank David Needleman, Ying Wang and Renata Ng at the Microbiology and Molecular Genetics Core facility for their technical assistance in performing the automated sequencing. Thanks also go to Jeff Gralnick for his technical assistance during the summer of 1996 . This work was entirely supported by a grant from the Clayton Foundation for Research.

\section{REFERENCES}

Allardet-Servent, A., Michaux-Charachon, S., Jumas-Bilak, E., Karayan, L. \& Ramuz, M. (1993). Presence of one linear and one circular chromosome in the Agrobacterium tumefaciens C58 genome. J Bacteriol 175, 7869-7874.

Ames, G. F.-L. (1986). Bacterial periplasmic transport systems: structure, mechanism and evolution. Annu Rev Biochem 55, $397-425$.

Bult, C. J., White, O., Olsen, G. J. \& 37 other authors (1996). Complete genome sequence of the methanogenic archaeon, Methanococcus jannaschii. Science 273, 1058-1073.

Cheng, H. \& Lessie, T. G. (1994). Multiple replicons constituting the genome of Pseudomonas cepacia 17616. J Bacteriol 176, $4034-4042$.

Choudhary, M., Mackenzie, C., Nereng, K. S., Sodergren, E. S., Weinstock, G. M. \& Kaplan, S. (1994). Multiple chromosomes in bacteria: structure and function of chromosome II of Rhodobacter sphaeroides 2.4.1 ${ }^{\mathrm{T}}$. J Bacteriol 176, 7694-7702.
Demolis, N., Mallet, L., Bussereau, F. \& Jacquet, M. (1995). Improved strategy for large-scale DNA sequencing using DNase I cleavage for generating random subclones. Biotechniques 18, 197-201.

Deutch, A. H., Rushlow, K. E. \& Smith, C. J. (1984). Analysis of the Escherichia coli proBA locus by DNA and protein sequencing. Nucleic Acids Res, 12, 6337-6355.

Dryden, S. C. (1992). Identification and characterization of the ribosomal RNA operons from Rhodobacter sphaeroides. PhD thesis, University of Illinois, Urbana-Champaign.

Dryden, S. C. \& Kaplan, S. (1990). Localization and structural analysis of the ribosomal RNA operons of Rhodobacter sphaeroides. Nucleic Acids Res 18, 7267-7277.

Ehlert, K., Holtje, J. \& Templin, M. F. (1995). Cloning and expression of a murein hydrolase lipoprotein from Escherichia coli. Mol Microbiol 16, 761-768.

Ferdows, M. S. \& Barbour, G. (1989). Megabase-sized linear DNA in the bacterium Borrelia burgodorferi, the Lyme disease agent. Proc Natl Acad Sci USA 86, 5969-5973.

Fichant, G. A. \& Burks, C. (1991). Identifying potential tRNA genes in genomic DNA sequence. J Mol Biol 220, 659-671.

Finan, T. M., Kunkel, B., Vos, G. F. W. \& Signer, E. R. (1986). Second symbiotic megaplasmid in Rhizobium meliloti carrying exopolysaccharide and thiamine synthesis genes. J Bacteriol 167, 66-72.

Fleischmann, R. D., Adams, M. D., White, O. \& 37 other authors (1995). Whole-genome random sequencing and assembly of Haemophilus influenzae Rd. Science 269, 496-512.

Fonstein, M. \& Haselkorn, R. (1995). Physical mapping of bacterial genomes. J Bacteriol 177, 3361-3369.

Frantz, B. \& Chakrabarty, A. M. (1986). Degradative plasmids in Pseudomonas. In The Bacteria, vol. X, The Biology of the Pseudomonads, pp. 295-323. Edited by J. R. Sokatch. New York: Academic Press.

Fraser, C. M., Jeannine, D. G., White, O. \& 26 other authors (1995). The minimal gene complement of Mycoplasma genitalium. Science 270, 397-403.

Freiberg, C., Perret, X., Broughton, W. J. \& Rosenthal, A. (1996). Sequencing the 500-kb GC-rich symbiotic replicon of Rhizobium sp. NGR234 using dye terminators and a thermostable 'sequenase': a beginning. Genome Res 6, 590-600.

Freiberg, C., Fellay, R., Balroch, A., Broughton, W. J., Rosenthal, A. \& Perret, X. (1997). Molecular basis of symbiosis between Rbizobium and legumes. Nature 387, 394-401.

Gest, H. (1972). Energy conservation and generation of reducing power in bacterial photosynthesis. Adv Microb Physiol 7, 243-282.

Glaser, P., Kunst, F., Arnaud, M. \& 14 other authors (1993). Bacillus subtilis genome project: cloning and sequencing of the $97 \mathrm{~kb}$ region from $325^{\circ}$ to $333^{\circ}$. Mol Microbiol 10, 371-384.

Hallenbeck, P. L., Lerchen, R., Hessler, P. \& Kaplan, S. (1990a). Roles of CfxA, CfxB, and external electron acceptors in regulation of ribulose 1,5-bisphosphate carboxylase/oxygenase expression in Rhodobacter sphaeroides. J Bacteriol 172, 1736-1748.

Hallenbeck, P. L., Lerchen, R., Hessler, P. \& Kaplan, S. (1990b). Phosphoribulokinase activity and regulation of $\mathrm{CO}_{2}$ fixation critical for photosynthetic growth of Rhodobacter sphaeroides. J Bacteriol 172, 1749-1761.

Himmelreich, R., Hilbert, H., Plagens, H., Pirkl, E., Li, Bi-Chen \& Herrmann, R. (1996). Complete sequence analysis of the genome of the bacterium Mycoplasma pneumoniae. Nucleic Acids Res 24, $4420-4449$. 
Kiley, P. J. \& Kaplan, S. (1988). Molecular genetics of photosynthetic membrane biosynthesis in Rhodobacter sphaeroides. Microbiol Rev 52, 50-69.

Kosuge, T., Tabata, K. \& Hoshino, T. (1994). Molecular cloning and sequence analysis of the proBA operon from an extremely therophilic eubacterium Thermus thermophilus. FEMS Micriobiol Lett 123, 55-62.

Krawiec, S. \& Riley, M. (1990). Organization of the bacterial chromosome. Microbiol Rev 54, 502-539.

Labedan, B. \& Riley, M. (1995). Gene products of Escherichia coli: sequence comparison and common ancestries. Mol Biol Evol 12, 980-987.

Lee, W. T., Terleshy, K. C. \& Tabita, F. R. (1997). Cloning and characterization of two groESL operons of Rhodobacter sphaeroides: transcriptional regulation of the heat-induced groESL operon. J Bacteriol 179, 487-495.

Lin, Y., Kieser, H. M., Hopwood, D. A. \& Chen, C. W. (1993). The chromosomal DNA of Streptomyces lividans 66 is linear. Mol Microbiol 10, 923-933.

Mackenzie, C., Chidambaram, M., Sodergren, E., Kaplan, S. \& Weinstock, G. M. (1995). Repair mutants of Rhodobacter sphaeroides. J Bacteriol 177, 3027-3035.

Mackenzie, C., Chidambaram, M., Choudhary, M., Nereng, K. S., Kaplan, S. \& Weinstock, G. M. (1997). Sequence skimming of chromosome II of Rhodobacter sphaeroides $2.4 .1^{\mathrm{T}}$. In Bacterial Genomes: Physical Structure and Analysis. Edited by F. J. de Bruijn, F. R. Lupski \& G. M. Weinstock. New York: Chapman \& Hall (in press).

Meijer, W. G. \& Tabita, R. (1992). Isolation and characterization of the nifUSVW-rpoN gene cluster from Rhodobacter sphaeroides. J Bacteriol 174, 3855-3866.

Michaux, S., Paillisson, J., Carles-Nurit, M.-J., Bourg, G., AllardetServent, A. \& Ramuz, M. (1993). Presence of two independent chromosomes in the Brucella melitensis $16 \mathrm{M}$ genome. $J$ Bacteriol $175,701-705$.

Moore, M. D. \& Kaplan, S. (1992). Identification of intrinsic highlevel resistance to rare-earth oxides and oxyanions in members of the class Proteobacteria: characterization of tellurite, selenite, and rhodium sesquioxide reduction in Rhodobacter sphaeroides. J Bacteriol 174, 1505-1514.

Neidle, E. L. \& Kaplan, S. (1992). Rhodobacter sphaeroides $r d x A$, a homolog of Rhizobium meliloti fixG, encodes a membrane protein which may bind cytoplasmic [4Fe-4S] clusters. J Bacteriol 174, 6444-6454.

Neidle, E. L. \& Kaplan, S. (1993). Expression of the Rhodobacter sphaeroides hemA and hem $T$ genes encoding two 5 -aminolevulinic acid synthase isozymes. J Bacteriol 175, 2292-2303.

Ogawa, J. \& Long, S. R. (1995). The Rhizobium meliloti groELc locus is required for regulation of early nod genes by the transcription activator NodD. Genes Dev 9, 714-729.
Omori, K., Suzuku, S., Imai, Y. \& Komatsubara, S. (1991). Analysis of the Serratia marcescens proBA operon and feedback control of proline biosynthesis. J Gen Microbiol 137, 509-517.

Pardo, M. A., Lagunez, J., Miranda, J. \& Martinez, E. (1994). Nodulating ability of Rhizobium tropici is conditioned by a plasmid-encoded citrate synthase. Mol Microbiol 11, 315-321.

Riley, M. (1993). Functions of the gene products of Escherichia coli. Microbiol Rev 57, 862-952.

Rodley, P. D., Romling, U. \& Burkhard, T. (1995). A physical genome map of the Burkbolderia cepacia type strain. Mol Micriobiol 17, 57-67.

Sambrook, J., Fritsch, E. F. \& Maniatis, T. (1989). Molecular Cloning: a Laboratory Manual, 2nd edn. Cold Spring Harbor, NY: Cold Spring Harbor Laboratory.

Schnier, J., Thamm, S., Lurz, R., Hussain, A., Faist, G. \& Dobrinski, B. (1988). Cloning and characterization of a gene from Rhizobium meliloti 2011 coding for ribosomal protein S1. Nucleic Acids Res 16, 3075-3089.

Sensen, C. W., Klenk, H., Singh, R. K. \& 10 other authors (1996). Organizational characteristics and information content of an archael genome: $156 \mathrm{~kb}$ of sequence from Sulfolobus solfataricus P2. Mol Microbiol 22, 175-191.

Sobral, B. W. S., Honeycutt, R. J., Atherly, A. G. \& McClelland, M. (1991). Electrophoretic separation of the three Rhizobium meliloti replicons. J Bacteriol 173, 5173-5180.

Suwanto, A. \& Kaplan, S. (1989). Physical and genetic mapping of the Rhodobacter sphaeroides 2.4.1 genome: presence of two unique circular chromosomes. $J$ Bacteriol 171, 5850-5859.

Suwanto, A. \& Kaplan, S. (1992). Chromosome transfer in Rhodobacter sphaeroides: Hfr formation and genetic evidence for two unique circular chromosomes. J Bacteriol 174, 1135-1145.

Tabita, F. R., Gibson, J. L., Bowien, B., Dijkhuizen, L. \& Meijer, W. G. (1992). Uniform designation for genes of the CalvinBenson-Bassham reductive pentose phosphate pathway of bacteria. FEMS Microbiol Lett 99, 107-110.

Woese, C. R., Stackebrandt, E., Weisburg, W. G. \& 8 other authors (1984). The phylogeny of the purple bacteria: the alpha subdivision. Syst Appl Microbiol 5, 315-326.

Yang, O., Oyaizu, Y., Oyaizu, H., Olsen, G. J. \& Woese, C. R. (1985). Mitochondrial origins. Proc Natl Acad Sci USA 82, 4443-4447.

Zuerner, R. L, Herrmann, J. L. \& Saint Girons, I. (1993). Comparison of genetic maps for two Leptospira interrogans serovars provides evidence for two chromosomes and intraspecies heterogeneity. J Bacteriol 175, 5445-5451.

Received 1 April 1997; revised 12 June 1997; accepted 17 June 1997. 